Wright State University

CORE Scholar

2008

\title{
A Construct Validation of the Neutral Objects Satisfaction Questionnaire (NOSQ)
}

Kevin J. Eschleman

Wright State University

Follow this and additional works at: https://corescholar.libraries.wright.edu/etd_all

Part of the Industrial and Organizational Psychology Commons

\section{Repository Citation}

Eschleman, Kevin J., "A Construct Validation of the Neutral Objects Satisfaction Questionnaire (NOSQ)" (2008). Browse all Theses and Dissertations. 884.

https://corescholar.libraries.wright.edu/etd_all/884

This Thesis is brought to you for free and open access by the Theses and Dissertations at CORE Scholar. It has been accepted for inclusion in Browse all Theses and Dissertations by an authorized administrator of CORE Scholar. For more information, please contact library-corescholar@wright.edu. 
A Construct Validation of the Neutral Objects Satisfaction Questionnaire (NOSQ)

A thesis submitted in partial fulfillment of the requirements for the degree of Master of Science

By

KEVIN JOSEPH ESCHLEMAN

B.A., University of California at Santa Cruz, 2005

2009

Wright State University 


\section{APPROVAL SheET (M.S.)}

Wright StATE UNIVERSITY

School of GRAduATE StUdies

NoVEMBER 20, 2008

I HEREBY RECOMMEND THAT THE THESIS PREPARED UNDER MY SUPERVISION BY Kevin J. Eschleman ENTITLED A CONSTRUCT VALIDATION OF THE NEUTRAL OBJECTS SATISFACTION QUESTIONNAIRE (NOSQ) BE ACCEPTED IN PARTIAL FULFILLMENT OF THE REQUIREMENTS FOR THE DEGREE OF Master of Science.

Nathan A. Bowling, Ph.D. Thesis Director

Daniel L. Weber, Ph.D. Graduate Program Director

Committee on

Final Examination

John M. Flach, Ph.D.

Chair, Department of Psychology

Corey E. Miller, Ph.D.

Martyn Whittingham, Ph.D.

Nathan A. Bowling, Ph.D.

Joseph F. Thomas, Jr., Ph.D.

Dean, School of Graduate Studies 


\begin{abstract}
Eschleman, Kevin Joseph. M.S., Department of Psychology, Wright State University, 2009. A Construct Validation of the Neutral Objects Satisfaction Questionnaire (NOSQ).
\end{abstract}

The current study is a construct validation of the Neutral Objects Satisfaction Questionnaire (NOSQ). The study includes tests of convergent and discriminant validity. Specifically, the NOSQ had more empirical overlap with affective-oriented dispositions (i.e., positive affectivity, negative affectivity, neuroticism, extraversion, trait anxiety, trait anger, trait depression, and cheerfulness) than with cognitive-oriented dispositions (i.e., need for cognition, general self-efficacy, and locus of control). In addition, the NOSQ had greater empirical overlap with the aforementioned affective-oriented dispositions than with a measure of temporal affect (i.e., mood). Correlations between the NOSQ and both job satisfaction and job cognitions were also compared, but no significant difference in correlation strength was found. Limitations, suggestions for future research, and the utility of the NOSQ in dispositional and job attitude research are discussed. 


\section{TABLE OF CONTENTS}

Introduction 1

Nature of Dispositions 3

Cognitive-Oriented Dispositions 3

Affective-Oriented Dispositions 5

Neutral Objects Satisfaction Questionnaire 7

Stability of the Neutral Objects Satisfaction Questionnaire 7

NOSQ and Affective-Oriented Dispositions 8

Proposed Nomological Net 10

Dispositional Basis of Job Satisfaction 15

Assessing Job Satisfaction and Job Cognitions 17

Neutral Objects Satisfaction Questionnaire and Job Satisfaction 18

Method 20

Participants and Procedure 20

Measures 20

Neutral Objects Satisfaction Questionnaire 20

Affective-oriented dispositions 21

Cognitive-oriented dispositions 22

Mood 23

Job satisfaction 24

Job cognitions 24

Analyses 25 
Results

Testing Hypotheses

Exploratory Analyses

Discussion 32

The NOSQ and Affective-Oriented Dispositions (H1a and H1b) 32

The NOSQ and Mood (H2a and H2b) 34

The NOSQ and Job Attitudes (H3a and H3b) 36

Implications and Future Research 37

Limitations 43

Conclusion 45

References 47

Table 1 61

Table 2 63

Table 3 66

Table 4 67

Table 5 68

Table 6 69

Appendix A 70

Table 7 70

Table 8 71

Table 9 72

Appendix B (Survey) 75 


\section{Acknowledgement}

There are many people that have contributed to the completion of this thesis. First and foremost, I would like to thank my family and friends for their emotional support throughout this experience. I would also like to thank the faculty, staff, and graduate students at Wright State University for their guidance and insight. Lastly, I would like to acknowledge the immeasurable support and patience of my adviser, Dr. Bowling. 
Neutral Objects Satisfaction Questionnaire 1

Introduction

Job satisfaction is the most widely researched variable in Industrial and Organizational Psychology (Spector, 1997). Satisfied employees commit fewer deviant behaviors (Dalal, 2005), have lower turnover intentions (Hellman, 1997), and engage in more citizenship behaviors (Lepine \& Johnson, 2002) than their dissatisfied counterparts. Given these outcomes, it is important for organizations to identify variables that predict job satisfaction. To predict an employee's job satisfaction, researchers assess situational variables (e.g., job characteristics; Hackman \& Oldham, 1976) and use measures of dispositions (e.g., Thoreson, Kaplan, Barsky, Warren, \& Chermont, 2003). One dispositional measure that was designed specifically to predict job satisfaction is the Neutral Objects Satisfaction Questionnaire (NOSQ), or the "The Gripe Index” (Weitz, 1952). The NOSQ is a 25 -item measure that instructs individuals to rate their affective response (i.e., degree of satisfaction) to objects an individual encounters on an everyday basis (Judge \& Bretz, 1993).

The relationship between the NOSQ and job satisfaction has been found to be moderate in strength and is likely to predict job satisfaction after controlling for common affective-oriented dispositions, such as positive affectivity (PA) and negative affectivity (NA; Eschleman \& Bowling, 2008). Eschleman and Bowling found that the relationship between the NOSQ and job satisfaction $(\rho=.34, k=8, N=1,391)$ is similar to the relationship between PA and job satisfaction $(\rho=.33, k=71, N=22,148$; Thoresen et al., 2003) and NA and job satisfaction $(\rho=-.37, k=145, N=52,120$; Thoresen et al., 2003). In addition, the NOSQ is only moderately correlated with PA $(\rho=.32, k=5, N=941$; Eschleman \& Bowling, 2008) and NA ( $\rho=-.27, k=7, N=1,442$; Eschleman \& Bowling, 
2008). Because the NOSQ predicts job satisfaction as well as both PA and NA, and has little empirical overlap with the constructs, the NOSQ is likely to predict job satisfaction even after both PA and NA are controlled. This prediction is supported by regression analyses using meta-analytic data in which the NOSQ explained an additional $4 \%$ of the variance in job satisfaction after controlling for PA and NA (Eschleman \& Bowling, 2008). In addition to correlating with job satisfaction, the NOSQ correlates with voluntary turnover ( $r=-.16$; Judge, 1993), job avoidance ( $r=.20$; Judge $\&$ Locke, 1993), and job strain $(r=-.23$; Zickar, Gibby, \& Jenny, 2003). The NOSQ also correlates with life satisfaction with a mean corrected correlation of $.44(k=10, N=2,031$; Eschleman \& Bowling, 2008) and explains an additional 5\% of the variance in life satisfaction when controlling for PA, NA, self-esteem, self-efficacy, locus of control, and neuroticism (Piccolo et al., 2005).

Although researchers use the NOSQ to assess an affective-oriented disposition (e.g., Judge \& Bretz, 1993; Hitlan et al., 2006), some researchers have begun to doubt this presumption (e.g., Fortunatto \& Goldblatt, 2002) because the NOSQ has little empirical overlap with common affective-oriented measures, such as PA and NA. The temporal stability of the NOSQ suggests the measure likely assesses a disposition (Carter, 2004; Judge \& Bretz, 1993) and the content of the items suggests that the measure is affective-oriented. Examples of these items include: "the city in which you live," "your first name," "8 1/2 x 11 piece of paper," "advertising," "the quality of food you buy," "television programs," and "the climate where you live." Because affective and cognitive-oriented dispositions will differentially predict affective and cognitive-oriented outcomes (e.g., Weiss, 2002), a better understanding of whether the content domain of 
the NOSQ construct is affective or cognitive-oriented will enable researchers to accurately apply the NOSQ in research and gain a better understanding of the antecedents of job satisfaction.

\section{The Nature of Dispositions}

Measures of psychological characteristics that predispose an individual to respond to the environment in a set manner include personality traits, need states, attitudes, preferences, and motives (House, Shane, \& Herold, 1996). Measures assessing these characteristics are measures of dispositions (i.e., traits) if they are relatively stable over time, whereas more temporal characteristics, such as attitudes or moods, are states (Davis-Blake \& Pfeffer, 1989; Staw \& Ross, 1985). Researchers assess dispositions by measuring an individual's tendency to engage in cognitive processes (e.g., Judge \& Bono, 2001b) and/or the tendency to experience affect (e.g., Judge \& Larson, 2001). Although cognition and affect are not independent systems, they are distinct (Zajonc, 1980). The current study refers to stable cognitive processes as cognitive-oriented dispositions and stable experiences of affect as affective-oriented dispositions. The subsequent review of cognitive and affective-oriented dispositions will describe the distinctions of the two systems in more detail.

Cognitive-oriented dispositions. Cognitive-oriented dispositions are an individual's consistencies in information processing and beliefs (Organ \& Near, 1985). Cognitive processes include needs, expectancies, encodings, and evaluations of the environment (Mischel \& Shoda, 1995). Examples of cognitive-oriented dispositions are need for cognition, general self-efficacy, and locus of control. Need for cognition is a person's tendency to engage in and enjoy thinking (Cacioppo \& Petty, 1982). An 
individual high in need for cognition both enjoys and consistently engages in an effortful cognitive process to gather, evaluate, and reflect upon information. An individual low in need for cognition enjoys activities that demand few cognitive resources and has a tendency to use heuristics and social comparisons (Cacioppo, Petty, Feinstein, \& Jarvis, 1996). A researcher should not consider need for cognition to be a need state. Need for cognition is a goal directed behavior that does not require an individual to do something in or to the environment, but rather is the individual's belief that effortful cognitive processes are more enjoyable (Cacioppo \& Petty, 1982).

General self-efficacy is a person's judgment of his or her ability to perform behaviors across situations (Bandura, 1986; Mitchell, Hopper, Daniels, George-Falvy, \& James, 1994). The judgment is a person's belief of self-confidence and ability level. Whereas general self-efficacy refers to the belief of self-confidence, locus of control represents a person's perceived ability to control outcomes and the beliefs an individual holds about the causes of events (Judge, Locke, Durham, \& Kluger, 1998). Individuals who believe the outcomes in their lives are the result of external causes (e.g., I did not get the promotion because my boss dislikes me) have an external locus of control, whereas individuals that believe the outcomes in their lives are contingent on their own behavior (e.g., I did not get the promotion because I did not work hard enough) have an internal locus of control (Levenson, 1981, Rotter, 1966). General self-efficacy and locus of control are commonly viewed as subconscious conclusions an individual reaches about him or herself through beliefs, expectations, and evaluations (Judge et al., 1998). Whereas cognitive-oriented dispositions include an evaluation process, affective-oriented 
dispositions include an individual's average level of a given emotion or tendency to have the same affective experience across situations (Judge \& Larson, 2001).

Affective-oriented dispositions. A common categorization of affect is in the form of a hierarchical structure. When ascending the hierarchy, constructs become more stable and lack a defining event or object. Affective-oriented dispositions are stable over time, whereas the affective states are more sensitive to fluctuations (e.g., Watson et al., 1988). Researchers often assess affective-oriented dispositions by evaluating the frequency of an emotion over the past few weeks, year, or in general, whereas measures of more temporal affect (affective states or moods) evaluate frequency of an emotion at that moment, over the past 24 hours, or in the past few days (Watson \& Tellegen, 1985). Moods are emotional responses that last only a few hours or days and are not directed at a specific object or person (Forgas, 1995). Moods differ from emotions in that emotions are directed at an object or person (e.g., you are angry at a co-worker; Cropanzano, Weiss, Hale, \& Reb, 2003). Emotions are partly derived from mood, which in turn are partly derived from affective-oriented dispositions (Watson, Clark, McIntyre, \& Hamaker, 1992; Watson \& Tellegen, 1985).

To assess the influence of affective-oriented dispositions, researchers often use positive affectivity (PA), negative affectivity (NA), extraversion, or neuroticism (Connolly \& Viswesvaran, 2000). PA and NA are conscious and subjective experiences. PA refers to an individual's tendency to respond to the environment with positive emotion and feel effectively engaged (Watson \& Tellegen, 1985). A person high in PA consistently experiences high energy, alertness, and enthusiasm (Watson, Clark, \& Tellegen, 1988). NA is an individual's tendency to respond to the environment with 
negative emotion (Watson \& Clark, 1984). For example, NA reflects subjective distress, anger, contempt, fear, and nervousness (Watson et al., 1988). A person high in NA will perceive the environment as being negative and have a tendency to report negative emotionality despite the absence of aversive conditions (e.g., Burke, Brief, \& George, 1993; Spector, Fox, \& Van Katwyk, 1999; Spector, Zapf, Chen, \& Frese, 2000).

Although PA and NA may appear to be bipolar opposites, there is little empirical overlap between the two dispositions (Connolly \& Viswesvaran, 2000; Diener \& Emmons, 1984; Watson \& Tellegen, 1985). For example, a meta-analysis by Connolly and Viswesvaran (1999) found a corrected correlation of -.30 between PA and NA $(k=56, N=13,496)$. Similar to PA and NA are the personality traits extraversion and neuroticism. Measures of PA correlate strongly with extraversion and measures of NA correlate strongly with neuroticism (e.g., Costa \& McCrae, 1994; Emmons \& Diener, 1985, 1986; McCrae \& Costa, 1992; Watson \& Clark, 1984, 1992). Extraversion is the tendency to engage in behaviors that demonstrate sociability, friendliness, assertiveness, and spontaneity. Individuals high on extraversion experience positive emotions (e.g., cheerful), seek excitement, and like people. Neuroticism is the tendency to engage in behaviors that represent differences in adjustment and emotional stability. Individuals high in neuroticism have a tendency to experience negative emotions (e.g., anxiety or anger).

Although PA and NA are affective-oriented, researchers argue that the measures of these constructs do not capture the entire affective content domain (Barrett \& Russell, 1998; Russell \& Barrett, 1999). For example, the Positive and Negative Affect Schedule (PANAS) primarily assesses high activation affect and should not to be considered a 
broad, all encompassing, measure of affect (Barrett \& Russell, 1999). Barrett and Russell (1998) argue that different measures capture different aspects of affect due to the format of the measures. Similarly, Russell and Barrett (1999) discuss the uncertainty among researchers in understanding the affective content domain and that not all aspects of affect can be accounted for with the same method of measurement. Therefore, researchers should use multiple scales with different formats when assessing the affective content domain. Differences in format and instructions can influence what content domain the measure is assessing. Temporal frame, for example, influences whether the PANAS assesses mood or disposition (e.g., Russell \& Carroll, 1999; Watson \& Tellegen, 1985). In addition, presenting participants with affective adjectives increases the amount of attention the participant provides toward the stimuli than when presenting a participant with a neutral word (MacLeod, Rutherford, Campbell, Ebsworthy, \& Holker, 2002; MacLeod \& Rutherford, 1998; Mathews \& MacLeod, 1994, Turvey, 1973). Thus, the item or stimuli that a measure presents can influence the reaction of the participant and the construct the measure is assessing. For a more comprehensive review of the competing theories of the structure of affect, refer to Cropanzano, Weiss, Hale, and Reb (2003). In sum, an interpretation of Barrett and Russell and Russell and Barrett's claim is not that PA and NA are inadequate representations of the affective content domain, but additional measures can assess the affective content domain while having little empirical overlap with PA and NA. The NOSQ is one such dispositional measure that may be assessing a unique portion of the affective content domain. 
Stability of the Neutral Objects Satisfaction Questionnaire. The stability of the Neutral Objects Satisfaction Questionnaire distinguishes the measure as assessing a disposition. Judge and Bretz (1993) demonstrated the stability of NOSQ by evaluating the test-retest reliability over a six-month period. In this study, the NOSQ had a corrected stability coefficient of .88. The NOSQ is also stable over a five-week period with a stability coefficient of .79 (Carter, 2004). In addition, when comparing the NOSQ to positive affectivity (PA) and negative affectivity (NA) in longitudinal studies, the NOSQ is more stable (Carter, 2004; Judge \& Bretz, 1993). By comparing the corrected stability coefficients of the NOSQ and the PANAS, Judge and Bretz find the NOSQ has a stability coefficient significantly stronger than PA (.16 increase) and NA (.17 increase). Carter (2004) provides support for Judge and Bretz in their study over a five-week period. In the study, the NOSQ has a stability coefficient significantly stronger than PA (.18 increase) and NA (.20 increase). The high test-retest reliability of the NOSQ is evidence that NOSQ is assessing a disposition.

NOSQ and affective-oriented dispositions. Although assumed by some researchers as a measure of negative affectivity (Probst, 2003), the NOSQ assesses a content domain different from common measures of affective-oriented dispositions (Carter, 2004; Eschleman \& Bowling, 2008; Fortunato and Goldblatt, 2002; Judge, Locke, Durham, \& Kluger, 1998; Piccolo, Judge, Takahashi, Watanabe, \& Locke, 2005). As discussed earlier, the NOSQ moderately correlates with PA and NA (Eschleman \& Bowling, 2008; Carter, 2004; Erez \& Judge, 1994; Judge \& Locke, 1993; Piccolo et al., 2005). The lack of empirical overlap between the NOSQ construct and affective-oriented dispositions extends beyond measures of positive and negative affectivity. Fortunato and 
Goldblatt (2002) compared various measures of affective-oriented dispositions to validate a revised version of a Strain-Free Negative Affectivity Scale. These measures assess various forms of negative affectivity, neuroticism, extraversion, and affect intensity. Although Fortunato and Goldblatt did not report all of the correlations between the measures, the two researchers find that the NOSQ correlates with the Multidimensional Personality Questionnaire, NEO Personality Inventory-Neuroticism (NEO-N), and the Eysenck Personality Inventory-Neuroticism (EPI-N) and Extroversion (EPI-E) and failed to significantly correlate with the Strain-Free Negative Affectivity Scale and the Affect Intensity Measure. Although the NOSQ correlates with four of these measures, the correlations are weak with the strongest correlation being .16 with the NEO-N and .12 with the EPI-N. The correlations of the NOSQ with other measures are substantially lower than the inter-correlations between the remaining affective-oriented measures $(\mathrm{r}=$ .37 to .81 ); thus, the NOSQ has little empirical overlap with these measures and is assessing a construct distinct from common affective-oriented dispositions.

Connolly and Viswesvaran (2000) suggest that the NOSQ has more empirical overlap with measures of NA than with measures of PA. The study is a meta-analysis on the relationship between job satisfaction and measures of affective-oriented disposition, PA, and NA. The affective-oriented disposition data was from a collection of seven studies, with six of the studies using the NOSQ. The seventh measure Connolly and Viswesvaran include in the affective-oriented disposition category is the Life Orientation Test. The Life Orientation Test is a measure of dispositional optimism, in which respondents rate their level of agreement with expected outcomes (e.g., In uncertain time, I usually expect the best; Scheier, Carver, \& Bridges, 1994). Researchers have not 
directly compared the NOSQ with the Life Orientation Test; therefore, Connolly and Viswesvaran should not have assumed the two measures empirically overlap. Although Connolly and Viswesvaran incorrectly pool data from the Life Orientation Test and the NOSQ, the meta-analysis provides additional insight on the relationship of the NOSQ with PA, NA, and job satisfaction.

In Connolly and Viswesvaran's meta-analysis, job satisfaction correlates with affective-oriented disposition, PA, and NA with corrected correlations of $.36, .49$, and .33 respectively. The researchers note that the correlation of affective-oriented disposition with job satisfaction is less than that of positive affectivity and almost equivalent in strength to the correlation with negative affectivity. An interpretation of these findings is that the NOSQ is assessing a content domain that is more similar to negative affectivity than positive affectivity because of the similarity in correlation strength with job satisfaction (Connolly \& Viswesvaran, 2000). The argument for this interpretation is refuted by the findings in a more comprehensive meta-analysis of PA and NA in which PA and NA correlate with job satisfaction with a corrected correlation of .33 and -.37, respectively (Thoreson, Kaplan, Barsky, Warren, \& Chermont, 2003). The meta-analysis has a sample size of 22,148 for PA and 52,120 for NA, whereas Connolly and Viswesvaran's study has a sample size of 3,326 for PA and 6,233 for NA. By using the more comprehensive meta-analysis, the difference in correlation strength no longer exists, nor does the support that the NOSQ is more closely related to NA than PA. An interpretation of the lack of empirical overlap between the NOSQ construct and other dispositions is that the NOSQ is assessing a distinct construct. By determining what 
measures converge and diverge with the NOSQ will provide a theoretical framework of the NOSQ construct.

\section{Proposed Nomological Net}

A nomological network is Cronbach and Meehl's (1955) view of construct validity and is the network of laws that restrict interrelationships between constructs and identifies what a construct can and cannot relate to. A nomological network is the theoretical framework of a construct. The framework can be obtained by assessing observable manifestations (e.g., survey responses) of the construct and by comparing the interrelationships with other observable manifestations of different constructs. If the observable manifestations, or survey responses, converge and empirically overlap, a researcher can infer the constructs conceptually overlap. For example, the NOSQ construct and negative affectivity are likely both affective-oriented and should thus have an empirical relationship.

In addition to identifying the nomological network by how constructs converge, the framework of a construct becomes more clear by identifying what the construct does not relate to, or diverges from. The NOSQ, for example, may be related with some affective-oriented variables, but this relationship is not sufficient to claim the NOSQ construct is affective-oriented. If the NOSQ consistently converges with other affectiveoriented variables and consistently diverges from cognitive-oriented variables, a researcher can infer the theoretical framework of the NOSQ construct to be more similar to affective-oriented constructs.

Although insight into the theoretical framework of the NOSQ can be obtained by comparing affective-oriented and cognitive-oriented variables, additional insight may be 
obtained by showing whether the NOSQ converges with constructs similar in specificity. The moderate correlation between the NOSQ and measures of both PA and NA may be because PA and NA are relatively broader than the NOSQ. An explanation for this prediction can be found by applying the theory of bandwidth-fidelity. Bandwidth-fidelity argues that variables of similar specificity will converge (Ashton, 1998; Schneider, Hough, \& Dunnette, 1996; Tett, Steele, \& Beauregard, 2003). Although there is no previous evidence to suggest the NOSQ is a more narrow disposition than PA and NA, in fact researchers originally conceptualized the NOSQ construct to be a broader assessment of affect (e.g., Judge \& Bretz, 1993), the current study includes several measures of narrow dispositions for analyses. Examining more narrow dispositions will provide empirical relationships unexplored by previous research.

To examine more narrow dispositions researchers have developed sub-facets of the Five Factor Model (FFM). Because extraversion and neuroticism correlate strongly with PA and NA respectively (e.g., Costa \& McCrae, 1994; Emmons \& Diener, 1985, 1986; McCrae \& Costa, 1992; Watson \& Clark, 1984, 1992), an examination of the subfacets of neuroticism and extraversion will indirectly provide a more specific (lower bandwidth) assessment of PA and NA and yield a stronger empirical relationship with the NOSQ. Neuroticism sub-facets include trait anxiety, trait anger, trait depression, selfconsciousness, impulsiveness, and vulnerability. Extraversion sub-facets include friendliness, gregariousness, assertiveness, activity level, excitement seeking, and cheerfulness (e.g., Costa \& McCrae, 1995; McCrae \& Costa, 1992). A review of the FFM sub-facet measures demonstrates four sub-facets to be clearly affective-oriented (i.e., trait 
anxiety, trait anger, trait depression, \& cheerfulness). Each of the four sub-facets pertains to the experiences of affect.

Trait anxiety is an individual's tendency to view the world negatively and to consistently feel distress (Spector, Jex, \& Chen, 1995). An example of a trait anxiety item is, "I am afraid of many things" (IPIP, 2001). An individual high in trait anxiety has a tendency to view situations as dangerous or threatening and has feelings of tension, apprehension, nervousness, and worry (Spielberger \& Sydeman, 1994). Trait depression is the tendency to feel "blue", sad (IPIP, 2001) and the experiences of dysphoria (Suls \& Bunde, 2005). An example of a trait depression item is, "I am afraid of many things" (IPIP, 2001). Although many researchers view trait depression and trait anxiety as having cognitive processes (e.g., Beck, Brown, Steer, Eidelson, \& Riskind, 1987; Clark, Beck, \& Stewart, 1990; Clark, Steer, \& Beck, 1994) in which individuals experience negative thought (e.g., loss, failure, or danger), trait depression and trait anxiety are also linked to the experiences of affect (e.g., Clark et al., 1990; Clark \& Watson, 1991; Watson \& Tellegen, 1985).

Trait anger is the subjective feelings of irritation, annoyance, and rage (Spielberger, Krasner, \& Solomon, 1988; Spielberger \& Sydeman, 1994). An example of a trait anger item is, "I am often in a bad mood" (IPIP, 2001). Individuals high in trait anger consistently perceive the world as anger provoking (Fox \& Spector, 1999) and more likely to experience the emotional state of anger (Deffenbacher, 1992; Spielberger, Krasner, \& Solomon, 1988; Speilberger \& Sydeman, 1994). Cheerfulness is an individual's tendency to experience joy, cheer, and positive emotions (Ruch, Kohler, \& Van Thriel, 1997). An example of a cheerfulness item is, "I radiate joy" (IPIP, 2001). 
If the NOSQ is assumed to assess an affective-oriented variable, then it should empirically overlap more with other affective-oriented disposition measures (i.e., PA, NA, neuroticism, extraversion, trait anxiety, trait anger, trait depression, and cheerfulness) than with cognitive-oriented disposition measures (i.e., need for cognition, generalized self-efficacy, and locus of control). No previous research was found that reports correlations of the NOSQ with trait anxiety, trait depression, trait anger, cheerfulness, or need for cognition, whereas only one study reports that the NOSQ correlates significantly with general self-efficacy $(r=.24)$ and non-significantly with locus of control (Piccolo et al., 2005). To test the hypothesis that the NOSQ is more affective than cognitive, the current study predicts the following:

Hypothesis la: The NOSQ will correlate negatively with the five affectiveoriented dispositions (i.e., negative affectivity, neuroticism, trait anxiety, trait anger, and trait depression) and correlate positively with three affective-oriented dispositions (i.e., positive affectivity, extraversion, cheerfulness).

Hypothesis $1 b$ : The NOSQ will correlate more strongly with affective-oriented dispositions (i.e., positive affectivity, negative affectivity, extraversion, neuroticism, trait anxiety, trait anger, trait depression, and cheerfulness) than with cognitive-oriented dispositions (i.e., need for cognition, general self-efficacy, and locus of control).

Although affective-oriented dispositions and mood relate, the two are distinct constructs and do not have a strong empirical overlap. The reasoning for the weak correlation between measures of the two constructs pertains to the concept of bandwidthfidelity. Affective-oriented dispositions are broad constructs relative to affective-oriented 
states. If the disposition the NOSQ is assessing is affective-oriented, the NOSQ should correlate with mood. However, the correlation of the NOSQ with measures of mood should be weaker than the correlation of the NOSQ with measures of affective-oriented constructs of similar bandwidth. Although Carter (2004) found the NOSQ correlates with mood, the correlation of the NOSQ with mood was less than with PA and NA. Thus:

Hypothesis $2 a$ : The NOSQ will correlate positively with positive mood. Hypothesis 2b: The NOSQ will correlate more strongly with affective-oriented dispositions (i.e., positive affectivity, negative affectivity, extraversion, neuroticism, trait anxiety, trait anger, trait depression, and cheerfulness) than with mood.

\section{Dispositional Basis of Job Satisfaction}

Dispositions can predispose an individual to respond positively or negatively to the job environment (Staw \& Ross, 1985). Research on the effect of dispositions on job satisfaction extends to include the genetic makeup of an individual. Identical twins reared apart are more similar in their satisfaction with their jobs than those genetically dissimilar; genetics explain $31 \%$ of the variance in general and intrinsic job satisfaction (Arvey, Bouchard, Segal, \& Abraham, 1989; Arvey, McCall, Bouchard, Taubman, \& Cavanaugh, 1993). PA and NA together explain $45 \%$ of the genetic influence on job satisfaction and the FFM explains $24 \%$ of the genetic influence on job satisfaction (Ilies \& Judge, 2003). Ilies and Judge (2003) provide evidence that current measures of dispositions directly assess stable individual characteristics and predict job satisfaction.

Staw and Ross (1985) argue that dispositions, rather than situational factors, are a better predictor an employee's satisfaction with his or her job. Staw and Ross use the 
high test-retest correlations of job satisfaction measures to infer a dispositional effect on job satisfaction (Dormann \& Zapf, 2001). Their reasoning is that if an employee's score on a job satisfaction measure remains relatively the same over time, then the stability of job satisfaction is likely due to stable individual characteristics within the individual rather than a variable environment. Although the test-retest correlations provide no direct evidence of dispositions, researchers can use the correlation to indirectly predict the maximum dispositional effect on job satisfaction (Dormann \& Zapf, 2001).

The effect of dispositions on job satisfaction is not without opposition. Gerhart (1987) and Davis-Blake and Pfeffer (1989) argue that situational factors play a dominant role in an individual's job satisfaction and that the stability of job satisfaction is most likely because of situational determinants that are stable over time. More recently, researchers accept the notion of both situational stability and dispositional stability affecting job satisfaction (Gerhart, 2005; Staw \& Cohen-Charash, 2005).

Measures of affective-oriented and cognitive-oriented dispositions significantly correlate with measures of job satisfaction. Igniting the interest in the affective-oriented disposition - job satisfaction relationship was Staw, Bell, and Clausen's (1986) longitudinal study (Thoreson, Kaplan, Barsky, Warren, \& Chermont, 2003). Staw et al. found measures of affective-oriented dispositions taken during adolescence moderately correlates $(r=.37)$ with job satisfaction of middle aged adults. Researchers emphasize the effect of affective-oriented dispositions on job satisfaction by observing the relationship in at least 145 studies and 52,120 people (Thoreson et al., 2003). Meta-analyses on positive affectivity (PA) and negative affectivity (NA) report significant correlations with job satisfaction; PA and NA correlate with job satisfaction with estimated true scores 
ranging from .34 to .49 and -.33 to -.34 respectively (Connolly \& Viswesvaran, 2000; Thoreson et al., 2003). In addition, meta-analyses on neuroticism $(p=-.29, k=92, N=$ 24,527) and extraversion ( $p=.25, k=75, N=20,184)$ report significant corrected correlations with job satisfaction (Judge, Heller, \& Mount, 2002). In relation to cognitiveoriented dispositions, meta-analyses on measures of general self-efficacy $(p=.45, k=12$, $N=12,903)$ and locus of control $(p=.32, k=80, N=18,491)$ report significant corrected correlations with job satisfaction (Judge \& Bono, 2001a).

Assessing job satisfaction and job cognitions. The dispositional effect on job satisfaction not only depends on whether the disposition is cognitive or affective-oriented (Weiss, 2002), but also depends on the measure of job satisfaction (e.g., Organ \& Near, 1985). Researchers theorize that job satisfaction is comprised of both a cognitive component and an affective component (Brief \& Roberson, 1989). In addition, social psychologists claim that attitude formulation includes both cognition and affect antecedents (e.g., Olson \& Zanna, 1993; Petty, Wegener, \& Fabrigar, 1997). Similar to dispositions, the cognitive component of job satisfaction is a decision making process. This decision making process requires the individual to make judgments by comparing job beliefs and the perception of the job environment (e.g., my job is better than my friend's job), whereas the affective component is an individual's automatic affective response (e.g., I hate my job; Organ \& Near, 1985). Although job satisfaction is an employee's affective response to the job, most measures of job satisfaction predominately comprise of cognitive assessment items (Brief, 1998; Brief \& Roberson, 1989; Organ \& Near, 1985). The incongruence between definition and measurement has led some researchers to assess job satisfaction with affective-oriented measures and use measures 
of job cognitions to assess an employee's job beliefs or evaluations of comparative worth (e.g., Cooper \& Scholl, 1989; Organ \& Konovsky, 1989; Scholl, Cooper, \& McKenna, 1987).

Affective-oriented dispositions are likely better predictors of affective criterion (Weiss, 2002); thus, the antecedents of job satisfaction are likely to differentially affect job satisfaction measures that are affective-oriented than measures of job cognitions. Affective Events Theory (AET) supports Weiss' claim by specifying that job cognitions will relate to cognitive-oriented behaviors, whereas affective reactions on the job relate to affective-oriented behaviors (Wegge, Van Dick, Fisher, West, \& Dawson, 2006; Weiss, 2002; Weiss \& Cropanzano, 1996). More specifically, AET states that affect at work will have an effect on an employee's job satisfaction that is distinguishable from the effect of job cognitions. In addition, an employee's affect at work is partially caused by affectiveoriented dispositions. In other words, affective-oriented dispositions will have an effect on the affective experiences on the job that in turn will have an effect on job satisfaction unique from cognitive evaluations.

Neutral Objects Satisfaction Questionnaire and job satisfaction. By applying AET to the NOSQ - job satisfaction relationship, if the NOSQ is assessing an affectiveoriented content domain, then it should have a stronger correlation with measures of affective-oriented attitudes than cognitive-oriented attitudes. A review of the measures of job satisfaction in studies assessing the NOSQ - job satisfaction relationship provides support for this prediction. Although the NOSQ correlates with general job satisfaction ( $p$ $=.34$ ), a weaker or non-significant relationship is found when job satisfaction is assessed with the Job Descriptive Index (JDI; Eschleman \& Bowling, 2008), a cognitive-oriented 
measure (Brief \& Roberson, 1989). Specifically, Eschleman and Bowling (2008) find the NOSQ has a relationship with the JDI measures of satisfaction with work itself $(p=.24, k$ $=4, N=1,130)$, supervision $(p=.12, k=5, N=1,353)$, pay $(p=.15, k=3, N=769)$, and co-workers $(p=.15, k=5, N=1,353)$ and a non-significant relationship with satisfaction with promotion $(k=3, N=769)$. In addition, the NOSQ has a weak correlation with an overall JDI score $(r=.17$; Judge, 2002).

The weaker relationship between the NOSQ and the JDI may be interpreted in two ways. First, the NOSQ is a broad construct and should predict broad measures of job satisfaction better than facet satisfaction (Aston, 1998; Schneider et al., 1996; Tett et al., 2003). The second interpretation pertains to the NOSQ being affective-oriented. If the NOSQ is affective-oriented, then the NOSQ should not predict cognitive-oriented attitudes as well as affective-oriented attitudes. Comparing the NOSQ with cognitive and affective-oriented attitudes will provide additional support that the NOSQ is assessing an affective-oriented content domain. In addition, because at least half of the studies examining the NOSQ - job satisfaction relationship use a cognitive-oriented measure, previous research may not be accurately assessing the effect of the NOSQ construct on job satisfaction. Thus:

Hypothesis $3 a$ : The NOSQ will correlate positively with a measure of job satisfaction that is affective-oriented.

Hypothesis $3 b$ : The NOSQ will correlate more strongly with a measure of job satisfaction that is affective-oriented than with job cognitions. 


\section{Method}

\section{Participants and Procedure}

Participants are from a mid-size Midwestern university. The employed participants worked a minimum of twenty hours per week and have twelve months job tenure. All participants in this study received extra credit for taking part and were selected from an introductory psychology participant pool. The participants completed the surveys individually in a classroom setting and were informed that all responses would be kept confidential. A power analysis was conducted for a $p$-value $<.05$, an effect size of .10, and a minimum power of .80. A total of 400 completed questionnaires were collected to account for unusable surveys and reach adequate power. Four participants provided incomplete data and were removed from the analyses. In addition, 79 participants did not meet the job requirements. Because Hypotheses 1 and 2 do not require work experience, the data from the participants not meeting the job requirements were included in the analyses to test Hypotheses 1 and 2. The total sample of 396 participants were an average of 19 years old, 70\% female, 64\% Caucasian, and 27\% African-American. A total of 317 participants successfully completed the survey and met the working requirements of twelve months job tenure and twenty hours worked per week. The employed sample was an average of 19 years old, $70 \%$ female, $69 \%$ Caucasian, and 24\% African-American. In addition, the employed sample worked an average of 26 hours per week and had 21 months job tenure.

\section{Measures}

Neutral Objects Satisfaction Questionnaire. The study includes a modified version of Weitz's (1952) original 44-item Neutral Objects Satisfaction Questionnaire 
(NOSQ). The modified version includes 25 -items asking an individual to rate his or her level of satisfaction with neutral objects common to everyday life (e.g., 8 1/2" x 11 " piece of paper, today's cars, advertising; Judge \& Bretz, 1993). Judge and Bretz (1993) exclude items from Weitz's original version because the items do not apply to all individuals (e.g., your last boss) or because the items were contaminated by socioeconomic status (e.g., the area of the city in which you live). The 25 -item instrument contains three response categories (i.e., $1=$ dissatisfied, $2=$ neutral, $3=$ satisfied). The study obtained a total score by calculating each respondent's average score across the NOSQ items. The alpha reliability in the current study was .83 .

Affective-oriented dispositions. To assess positive and negative affectivity the current study used two ten-item measures from Watson, Clark, and Tellegen, (1988). Respondents rated how often they feel an emotion "in general, that is, on average". Each item is scored on a 5-point Likert-type scale that ranges from never (1) to always (5). The ten positive affectivity (e.g., enthusiastic, interested, inspired) items have an alpha reliability of .88 and the ten negative affectivity items (e.g., jittery, afraid, upset) have an alpha reliability of .87 (Watson, Clark, \& Tellegen, 1988). The alpha reliability in the current study was .81 for both PA and NA. To assess extraversion, neuroticism, anxiety, depression, anger, and cheerfulness the study used ten-item measures from the International Personality Item Pool (2001). The measures instructed the respondent to rate each item on how accurately the item described their behaviors in general. Each instrument contains five response options (i.e., $1=$ strongly disagree, 2 = disagree, $3=$ neither agree nor disagree, $4=$ agree, $5=$ strongly agree) and the study reverse scored negatively keyed items. Extraversion was assessed with five positively keyed items (e.g., 
feel comfortable around people) and five negative keyed items (e.g., have little to say). IPIP (2001) reports an alpha reliability of .86 for the instrument, whereas the alpha reliability in the current study was .81 . Neuroticism was assessed with five positively keyed items (e.g., am often down in the dumps) and five negative keyed items (e.g., rarely get irritated). IPIP (2001) reports an alpha reliability of .86 for the instrument, whereas the alpha reliability in the current study was .80 . Anxiety was assessed with five positively keyed items (e.g., worry about things, fear for the worst) and five negatively keyed items (e.g., am not easily bothered by things, am relaxed most of the time). IPIP (2001) reports an alpha reliability of .83 for the instrument, whereas the alpha reliability in the current study was .79. Anger was assessed with five positively keyed items (e.g., get angry easily, get irritated easily) and five negatively keyed items (e.g., rarely get mad, am not easily annoyed). IPIP (2001) reports an alpha reliability of .83 for the instrument, whereas the alpha reliability in the current study was .87 . Depression was assessed with seven positively keyed items (e.g., often feel blue, dislike myself, feel desperate) and three negatively keyed items (e.g., feel comfortable with myself). IPIP (2001) reports an alpha reliability of .88 for the instrument, whereas the alpha reliability in the current study was .85. Cheerfulness was assessed with eight positively keyed items (e.g., radiate joy, love life, look at the bright side of life) and two negatively keyed items (e.g., am not easily amused). IPIP (2001) reports an alpha reliability of .81 for the instrument, whereas the alpha reliability in the current study was .74 .

Cognitive-oriented dispositions. A total score was obtained for each cognitiveoriented disposition by calculating the respondent's average score on each item. Each measure was scored on a 5-point Likert-type scale from strongly disagree (1) to strongly 
agree (5). Negatively keyed items were reverse scored. The New General Self-efficacy Scale (NGSE) from Chen, Gully, and Eden (2001) is used to assess generalized selfefficacy. The NGSE is an eight-item measure (e.g., I will be able to achieve most of the goals that I have set for myself, I believe I can succeed at most any endeavor to which I set my mind) with an alpha reliability of .85 and .86 (Chen et al., 2001). The alpha reliability in the current study was .83 . Need for cognition and locus of control were assessed with measures from the International Personality Item Pool (2001). Respondents rated each item on how accurately the items described their behaviors in general. The study reverse scored negatively keyed items. The study assessed need for cognition with a 10-item measure that includes six positively keyed items (e.g., like to solve complex problems, love to think up new ways of doing things, need things explained only once) and four negatively keyed items (e.g., avoid philosophical discussions, avoid difficult reading material). The IPIP (2001) reports an alpha reliability of .84 for the instrument, whereas the alpha reliability in the current study was.78. The study assessed locus of control with a 20 -item measure that includes ten positively keyed item (i.e., believe that my success depends on ability rather than luck) and ten negatively keyed items (e.g., believe in the power of fate). High scores indicate high internal locus of control. The IPIP (2001) reports an alpha reliability of .86 for this instrument, whereas the alpha reliability in the current study was .82 .

Mood. The study assessed mood with a four-item measure from Sinclair, Mark, Enzle, Borkovec, and Cumbleton (1994). Respondents rated how they feel "right now, today." Each item is bipolar (i.e., very passive-very active, very happy-very sad, very depressed-very elated, very excited-very tranquil) and items have anchors of 1 and 7 . The 
study obtained a total score by calculating each respondent's average score. Sinclair and colleagues report alpha reliabilities of .92 and .83 for the instrument, whereas the alpha reliability in the current study was .71.

Job satisfaction. The study assessed an employee's affective reaction to the job (job satisfaction) with the Michigan Organizational Assessment Questionnaire (MOAQ; Cammann, Fichman, Jenkins, \& Klesh, 1983). The MOAQ is a predominately affective measure of job satisfaction because it strongly correlates $(r=.73)$ with the Job-related Affective Well-Being Scale, a measure of affect in the work place (Van Katwyk, Fox, Spector, \& Kelloway, 2000), and consistently correlates with affective-oriented variables in a meta-analysis examining the validity of the MOAQ (e.g., affective commitment, frustration, depression, anxiety; Bowling \& Hammond, 2008). The MOAQ contains a three-item scale in which individuals provide overall affective responses to his or her job (i.e., all in all I am satisfied with my job, in general I don't like my job, in general I like working here). Respondents rated their level of agreement with these items using a 5point scale ranging from strongly disagree (1) to strongly agree (5). The measure includes one item that was reverse scored. An average of the three items yielded a total score for the measure. The alpha reliability in the current study was .91.

Job cognitions. The study assessed an employee's beliefs about the job (job cognitions) with a six-item measure adopted from Scholl, Cooper, and McKenna (1987) and Organ and Konovsky (1989). The measure instructs respondents to assess their job using a 5-point scale ranging from very bad (1) to very good (5). Items include job comparisons with other employees with similar and different duties, equivalent education, of same age cohort, and overall evaluation of their current job status (e.g., 
Neutral Objects Satisfaction Questionnaire 25

How good is your job compared to similar individuals in this company who have this job). Previous research reports an alpha reliability of .87 for this instrument (Organ \& Konovsky, 1989), whereas the alpha reliability in the current study was .83 .

Analyses

The study calculated bivariate correlations to test if the NOSQ correlates with affective-oriented dispositions (Hypothesis 1a), mood (Hypothesis 2a), and a measure of job satisfaction that is affective-oriented (Hypothesis 3a). The study will have support for Hypothesis 1a with significant negative correlations between the NOSQ and NA, neuroticism, trait anxiety, trait anger, and trait depression and with a significant positive correlation between the NOSQ and PA, extraversion, and cheerfulness. Support for Hypothesis $2 \mathrm{a}$ will be found with significant correlations between the NOSQ and positive mood. Support for Hypothesis 3a will be found with a significant positive correlation between the NOSQ and job satisfaction.

Analyses for Hypotheses $1 \mathrm{~b}, 2 \mathrm{~b}$, and $3 \mathrm{~b}$ require the comparison of correlations. Hypothesis $1 \mathrm{~b}$ predicts the NOSQ will correlate more strongly with affective-oriented dispositions (i.e., positive affectivity, negative affectivity, neuroticism, extraversion, trait anxiety, trait anger, trait depression, and cheerfulness) than with cognitive-oriented dispositions (i.e., need for cognition, generalized self-efficacy, and locus of control). Hypothesis $2 \mathrm{~b}$ predicts the NOSQ will correlate more strongly with affective-oriented dispositions (i.e., positive affectivity, negative affectivity, neuroticism, extraversion, trait anxiety, trait anger, trait depression, and cheerfulness) than with mood. Hypothesis $3 \mathrm{~b}$ predicts the NOSQ will correlate more strongly with a measure of job satisfaction that is affective-oriented than with job cognitions. To determine if the differences between 
correlations are significantly different, the study will conduct $t$-tests for dependent samples (Bruning \& Kints, 1977). The analyses are repeated for each comparison of correlations.

Additional $t$-tests were conducted to evaluate the effect of overlapping items between cognitive and affective-oriented scales. The locus of control measure had three overlapping items with depression (I dislike myself, I feel comfortable with myself, and I feel my life lacks direction), two overlapping items with neuroticism (I dislike myself and I feel comfortable with myself), and one overlapping item with cheerfulness (I love life). Although these items are not face valid with the conceptualization of locus of control, the items were included in the study because the locus of control measure has been shown to be a valid assessment of the construct (IPIP, 2001). Nonetheless, it is not surprising that locus of control has some empirical overlap with affective-oriented dispositions (e.g., Judge et al., 2002). As a precaution, the $t$-test comparisons were conducted with all of the overlapping items included and with the items excluded; the overlapping items yielded no changes in the significant levels of the $t$-tests for dependent samples. 


\section{Results}

The means, standard deviations, internal consistency reliabilities, and correlations calculated for the variables are reported in Table 1. Correlations corrected for unreliability (Crocker \& Algina, 1986) are presented above the diagonal, whereas uncorrected correlations are presented below the diagonal. Although the corrected correlations are not required to test the hypotheses of the current study, the correlations describe the underlying relationships with the NOSQ construct. Table 1 also includes the total number of participants that successfully completed each scale.

\section{Testing Hypotheses}

Support was found for both Hypothesis $1 \mathrm{a}$ and $1 \mathrm{~b}$. Hypothesis 1a predicts the NOSQ will significantly correlate with each of the affective-oriented dispositions. As presented in Table 1 , the NOSQ significantly correlates $(p<.01)$ with each of the affective-oriented dispositions: positive affectivity $(r=.32)$, negative affectivity $(r=$ $.22)$, extraversion $(r=.22)$ neuroticism $(r=-.30)$, trait anxiety $(r=-.21)$, trait depression $(r=-.34)$, trait anger $(r=-.23)$, and cheerfulness $(r=.29)$. Table 2 reports the findings from the $t$-tests for dependent samples (Bruning \& Kintz, 1977). Each cell contains the correlation difference and the significance level. These findings provide support for Hypothesis $1 \mathrm{~b}$ in which the NOSQ would have a stronger correlation with the affectiveoriented dispositions when compared to the cognitive-oriented dispositions. The NOSQ had significantly stronger correlations in 11 of 24 comparisons: positive affectivity vs. need for cognition $(t=5.77, p<.01)$, positive affectivity vs. general self-efficacy $(t=1.92$, $p<.05)$, negative affectivity vs. need for cognition $(t=3.58, p<.01)$, neuroticism vs. need for cognition $(t=5.29, p<.01)$, extraversion vs. need for cognition $(t=3.58, p<.01)$, trait 
anxiety vs. need for cognition $(t=3.39, p<.01)$, trait anger vs. need for cognition $(t=$ $3.78, p<.01)$, trait depression vs. locus of control $(t=2.01, p<.01)$, trait depression vs. need for cognition $(t=6.28, p<.01)$, trait depression vs. general self-efficacy $(t=2.28$, $p<.01)$, and cheerfulness vs. need for cognition $(t=5.06, p<.01)$. In no cases were the correlations significantly stronger for the cognitive-oriented dispositions. The average correlation between the NOSQ and affective-oriented dispositions was .27, whereas the average correlation between the NOSQ and cognitive-oriented dispositions was only .15. In addition, the differences between correlation strengths were in the predicted direction in 20 of 24 comparisons. A sign test was conducted and the ratio of correlations in the direction toward the affective-oriented dispositions was found to be statistically significant $(p<.001)$.

To further examine Hypothesis $1 \mathrm{~b}$, the current study conducted two regression analyses. In the first analysis, reported in Table 5, the NOSQ was regressed on all three cognitive-oriented dispositions in step 1 and then all eight affective-oriented dispositions were added in step 2. Affective-oriented dispositions yield a unique relationship with the NOSQ when controlling for the three cognitive oriented dispositions $\left(R^{2}\right.$ change $=.09, p$ $<.01)$. The second analysis switched the ordered predictors and found that cognitiveoriented dispositions yielded a unique relationship with the NOSQ after controlling for the affective-oriented dispositions $\left(R^{2}\right.$ change $\left.=.02, p<.01\right)$. In addition, the total variance explained when the NOSQ is regressed on all dispositions $\left(R^{2}=.18, p<.01\right)$ is moderate in size. The difference in unique variance explained is evidence that the NOSQ is more closely related to affective-oriented than cognitive-oriented dispositions. 
Support for Hypothesis $2 \mathrm{a}$ is found with a significant correlation between the NOSQ and positive mood $(r=.16$; Table 2$)$. Hypothesis $2 \mathrm{~b}$, the NOSQ will correlate more strongly with affective-oriented dispositions than with mood, is also supported and presented in Table 3. The differences between correlation strength were in the predicted direction in all eight comparisons. Of the eight comparisons, four are statistically significant: positive affectivity vs. $\operatorname{mood}(t=2.59, p<.01)$, neuroticism vs. $\operatorname{mood}(t=$ 2.22, $p<.01)$, trait depression vs. $\operatorname{mood}(t=2.96, p<.01)$, and cheerfulness vs. $\operatorname{mood}(t$ $=2.05, p<.01)$.

Regression analyses, following the same methods as those conducted for testing Hypothesis $1 \mathrm{~b}$, were conducted in regards to Hypothesis $2 \mathrm{~b}$ (Table 6). The NOSQ was regressed onto two ordered predictors: affective-oriented dispositions and mood. Affective-oriented dispositions yield a unique relationship with the NOSQ when controlling for mood $\left(R^{2}\right.$ change $\left.=.13, p<.01\right)$, whereas mood did not yield a unique relationship with the NOSQ when controlling for affective-oriented dispositions.

Hypothesis $3 \mathrm{a}$ is supported with a significant correlation between the NOSQ and job satisfaction $(r=.19, p<.01$; Table 1$)$. Hypothesis $3 \mathrm{~b}$ predicted the NOSQ to correlate more strongly with an affective-oriented measure of job satisfaction when compared with job cognitions. Contrary to prediction, the NOSQ did not have a stronger correlation with job satisfaction than with job cognitions. In addition, the difference in correlation strength was in the opposite direction than predicted; however, this difference was not significant (Table 4). 


\section{Exploratory Analyses}

Although not specifically predicted in the study, the affective-oriented dispositions chosen were done so partly because the NOSQ may be more closely related to sub-facets of the neuroticism or extraversion (see Appendix A). Additional analyses showed that trait anger $(r=-.23, p<.01)$, trait anxiety $(r=-.21, p<.01)$, and trait depression $(r=-.34, p<.01)$ did not correlate more strongly with the NOSQ than did neuroticism $(r=-.30, p<.01)$. However, depression did correlate more strongly than NA $(r=-.22, p<.01)$. Cheerfulness $(r=.29, p<.01)$ did not differ in correlation strength from PA $(r=.32, p<.012)$ or extraversion $(r=.22, p<.01)$. As a result, the weak correlations between the NOSQ and both PA and NA are likely because of factors other than bandwidth-fidelity.

The current study also conducted analyses that explored the relationship between the NOSQ and job attitudes after controlling for other dispositions (see Appendix A; Table 7). The NOSQ predicted unique variation in job satisfaction controlling for PA and NA $\left(R^{2}\right.$ change $\left.=.01, p<.05\right)$. This finding is consistent with previous regression analyses using meta-analytic data (Eschleman \& Bowling, 2008). Analyses unique to this study find that the NOSQ predicted unique variation in job cognitions when PA and NA are controlled $\left(R^{2}\right.$ change $\left.=.02, p<.01\right)$. In addition, the NOSQ predicted unique variation in job cognitions when all affective-oriented and cognitive-oriented dispositions were controlled $\left(R^{2}\right.$ change $\left.=.01, p<.05\right)$.

Table 8 of Appendix A reports the unique variation explained in the NOSQ by PA/NA and the cognitive-oriented dispositions. These results are similar to those presented in Table 5, but included fewer affective-oriented dispositions. A potential 
argument against the results presented in Table 5 is that the regression analyses included a greater number of affective-oriented dispositions compared to cognitive-oriented dispositions. It is likely that reducing the number of affective-oriented dispositions to be equal to the number of cognitive-oriented dispositions will reduce the discrepancy in the amount of unique variance explained. Table 8 reports that the inclusion of only two affective-oriented dispositions (i.e., PA and NA) yielded a unique relationship with the NOSQ $\left(R^{2}\right.$ change $\left.=.05, p<.01\right)$ that was stronger than the unique relationship yielded by the three cognitive-oriented dispositions $\left(R^{2}\right.$ change $\left.=.02, p<.05\right)$.

Table 9 of Appendix A compares the relationships between the NOSQ and affective-oriented dispositions with the relationships between the NOSQ and cognitiveoriented dispositions. These results are similar to those presented in Table 2, but include correlations corrected for unreliability. A potential argument against the results presented in Table 2 is that the reliability of each measure is influencing the relationship with the NOSQ. In other words, the relationship between the NOSQ and a cognitive-oriented disposition will be weakened because of the unreliability in each measure. Table 9 reports correlations corrected for unreliability and compares these relationships with $95 \%$ confidence intervals. 16 of 24 comparisons included confidence intervals that exclude the opposing correlation. In other words, 16 of 24 comparisons were significantly stronger in the direction of the affective-oriented dispositions. These results are similar to those presented in Table 2 . 


\section{Discussion}

The current study supports previous findings that the NOSQ has little empirical overlap with common disposition measures (Eschleman \& Bowling, 2008). In addition, the NOSQ converges with affective-oriented dispositions and diverges from cognitiveoriented dispositions. Support was found for two of the three hypotheses. The subsequent discussion provides potential explanations for the findings of this study as well as implications the study may have on future research involving affective-oriented dispositions.

\section{The NOSQ and Affective-Oriented Dispositions (H1a and H1b)}

The current study provides evidence that the NOSQ correlates more strongly with affective-oriented dispositions than with cognitive-oriented dispositions. In comparing the correlation strength between the NOSQ and eight affective-oriented dispositions to the correlation strength between the NOSQ and three cognitive-oriented dispositions, the NOSQ consistently had more empirical overlap with the affective-oriented dispositions. Only four of the comparisons were not in the predicted direction. In fact, no comparison yielded a significantly stronger correlation with the cognitive-oriented dispositions. Additional support is found when the average correlation between affective-oriented dispositions with the NOSQ was stronger than the average correlation between cognitiveoriented dispositions and the NOSQ.

Although $t$-tests comparing correlations for dependent means provide support for Hypothesis 1b, the current study included additional analyses to establish a baseline for comparison. These analyses consisted of $t$-tests to compare correlation strengths for PA, NA, and each of the cognitive-oriented dispositions. It would be expected that if the 
NOSQ is indeed affective-oriented, then the correlation comparisons should be similar to that of other well established affective-oriented dispositions. The NOSQ had a greater convergence with affective-oriented dispositions than did either PA or NA. PA was more strongly correlated with the seven remaining affective-oriented dispositions in only five of twenty-one comparisons. Two comparisons were significantly stronger in the direction of the affective-oriented dispositions and twelve comparisons were significantly stronger in the direction of the cognitive-oriented dispositions. NA was more strongly correlated with seven remaining affective-oriented dispositions in sixteen of twenty-one comparisons. Ten comparisons were significantly stronger in the direction of the affective-oriented dispositions and two comparisons were stronger in the direction of the cognitive-oriented.

A notable point of these findings is that both PA and NA significantly correlated with cognitive-oriented dispositions in some cases, whereas the NOSQ did not. Because PA and NA are well established in research as being affective-oriented dispositions (Connolly \& Viswesvaran, 2000; Thoreson et al., 2003; Watson \& Clark, 1984), and the NOSQ diverged from cognitive-oriented dispositions as well as or better than PA or NA, it may be that the nomological net of the NOSQ is more affective-oriented than those of PA or NA. Further discussion of the cognitive nature of PA and NA is provided in the subsequent summary and implications for future research. In the very least, the NOSQ can be considered to be assessing an affective-oriented content domain that has little empirical overlap with the current well-established affective-oriented measures.

Insight regarding the nomological net of the NOSQ is also provided by the regression analyses in Table 3 . The current study found that affective-oriented 
dispositions account for a greater portion of unique variance in the NOSQ when controlling for the cognitive-oriented dispositions than did the cognitive-oriented dispositions when controlling for the affective-oriented dispositions. An argument could be made that the greater unique variance explained is primarily due to the greater number of affective-oriented dispositions included in the analyses compared to cognitive-oriented dispositions. These analyses were re-run including only PA and NA as measures of affective-oriented dispositions and found similar results; PA and NA yielded a unique relationship with the NOSQ that was stronger than the unique relationship yielded by the three cognitive-oriented dispositions. By comparing both correlation strengths and conducting regression analyses, the current study provides evidence that the NOSQ is affective-oriented.

These analyses also provide evidence that the NOSQ is assessing a content domain unique from other common disposition measures. The total variance explained when the NOSQ is regressed on all eleven dispositions included is only moderate in size. Because the eleven dispositions do not account for a majority of the variability in the NOSQ, the NOSQ is likely assessing a unique content domain and is expected to explain unique variance in attitudes and behaviors after controlling for other dispositions. These outcome variables are discussed in the subsequent discussion on future research involving the NOSQ.

\section{The NOSQ and Mood (H2a and H2b)}

The significant correlation between the NOSQ and mood is evidence that the two constructs have some empirical overlap. Although the correlation is weak, the results still coincide with the hypothesized outcomes as well as previous empirical comparisons 
between the NOSQ and mood (i.e., Carter, 2004). Because the correlations between the NOSQ and affective-oriented dispositions are moderate in strength at best, the weak correlation between the NOSQ and mood recorded in the study is not surprising. In addition, it is expected that positive affectivity and negative affectivity would correlate more strongly with mood than would the NOSQ. The reason for this is that the format of the self-report measure for PA and NA presents the individual with an affective stem item. This affective stimulus may cause the information recall that takes place during retrospective self-report methods to be contaminated with the person's mood (Forgas, 1995), thus strengthening the correlation. The moderate relationship between retrospective measures of affect and mood has been predicted in previous research (e.g., Ross, 1989), therefore, it is not surprising to find the NOSQ to have a weaker correlation with mood than other common affective-oriented dispositions. It should be noted that mood was placed earlier in the survey than the affective-oriented dispositions (e.g., PA, NA, and NOSQ) to limit order effects on the correlations.

In support of Hypothesis $2 b$, the NOSQ correlates more strongly with affectiveoriented dispositions than with mood. Because previous research has established the NOSQ to be a stable disposition (Carter, 2004; Judge \& Bretz, 1993), the NOSQ should only weakly correlate with temporal experiences of affect. Although Hypothesis $2 \mathrm{~b}$ does not examine the stability of the NOSQ, only a longitudinal study could provide that evidence, the divergence with mood provides some evidence for the dispositional basis of the NOSQ and provides a better understanding of the NOSQ content domain. Thus, when constructing the nomological net of the NOSQ, mood is a distant correlate of the NOSQ construct relative to affective-oriented dispositions. 
The NOSQ and Job Attitudes (H3a and H3b)

The correlation between the NOSQ and job satisfaction was significant, but weaker than expected. In fact, the correlation between the NOSQ and job satisfaction was weaker than the correlation between the NOSQ and job cognitions; however, this difference was not statistically significant. The unexpected results extend beyond the relationship between the NOSQ and job attitudes to include the relationships between job attitudes and well-established affective-oriented measures. The difference in correlation strength between PA and job satisfaction compared to PA and job cognitions was also in the direction of job cognitions. NA was weakly correlated with job satisfaction and had a non-significant relationship with job cognitions. In addition, mood had a non-significant relationship with job satisfaction. Because the surprising and anomalous findings are not unique to the relationships that include the NOSQ, the inconsistent results should not be used to infer problems with the NOSQ measure or that the content domain is not affective-oriented. The subsequent discussion provides several alternative explanations.

First, the measure of job satisfaction (MOAQ) used in the current study may not be affective-oriented. Although this explanation is possible, existing evidence suggests that it is unlikely. The MOAQ correlates strongly with the Job Affective Well-being Scale (Van Katwyk, Spector, \& Kelloway, 2000). In addition, a meta-analysis on the MOAQ reports the measure correlating strongly with several affective-oriented variables (e.g., affective commitment, frustration, depression, anxiety; Bowling \& Hammond, 2008). Second, it could be argued that the measure of job satisfaction and job cognitions were assessing the same construct. However, the correlation between job satisfaction and job cognitions, in the current study, is moderate in strength indicating that the two 
measures are assessing similar but distinct content domains. Because the first two explanations are unlikely, the weaker than expected NOSQ-job satisfaction correlation is potentially due to the sample rather than the measures used.

The current study required participants to have twelve months job tenure and be working twenty hours per week; however, the study was unable to check and enforce this requirement. To avoid the possibility of participants lying in order to participate in the study, all individuals who arrived for the survey were allowed to participate and receive credit. The participants who did not report the necessary work requirements were not included in the analyses for Hypothesis 3. Although the study made efforts to avoid participants falsely reporting work experience, the potential contamination is still possible and could explain the unexpected results. In summary, despite the lack of support for Hypothesis 3b, the findings should not be used as evidence against the NOSQ being affective-oriented. When the other affective-oriented dispositions were compared with job satisfaction and job cognitions, similar findings were found; no affectiveoriented measure had a significantly different correlation with job satisfaction compared to job cognitions. These findings are likely the result of either the job attitude measures or the sample collected.

\section{Implication and Future Research}

Future research should continue the application of the NOSQ to provide insight into the relationship between the NOSQ and various affective-oriented outcome variables. The current study provides evidence that the NOSQ is affective-oriented and largely independent from other dispositions. Therefore, the NOSQ will likely yield incremental variance when trying to predict affective-oriented outcomes. Previous 
research involving the NOSQ and affective-oriented outcome variables have found a correlation between the NOSQ and both counterproductive work behaviors (Schneider, Hitlan, \& Radhakrishnan, 2000) and job strain (Zickar, Gibby, \& Jenny, 2004), however, many relationships have not been explored. For example, the NOSQ could be used as a control variable when exploring the correlates of burnout or emotional exhaustion. Although these relationships should be explored using the NOSQ, the measure is most notably valuable when assessing job attitudes.

Additional analyses show that the NOSQ predicted unique variation in job satisfaction and job cognitions when controlling for some or all of the remaining dispositions. The regression analyses are evidence that the NOSQ is a valuable dispositional measure that can be used in predicting job attitudes above and beyond other affective-oriented dispositional measures. Previous research has found evidence of a partial spuriousness relationship between job satisfaction and life satisfaction that is caused by dispositions (Heller, Judge, \& Watson, 2002). Future research examining this spurious relationship may find a more robust effect if the studies include the NOSQ. Because the NOSQ is a measure of a person's tendency to be satisfied, and has little empirical overlap with other dispositions, the measure will likely account for a unique portion of the relationship between job and life satisfaction after controlling for other common dispositions.

Future research should consider additional comparisons between existing affective-oriented disposition measures. As mentioned in the previous literature review, the NOSQ is more stable than measures of PA and NA (Carter, 2004; Judge \& Bretz, 1993). However, comparisons in stability of the NOSQ, PA, and NA are limited to only 
two studies. Future studies should examine the stability of the NOSQ and why it is a more stable measure than PA or NA. Because the stability of a measure is an indication the measure is assessing a disposition, future research should include the NOSQ when assessing the heritability of dispositional measures. The greater stability, for example, may indicate a greater proportion of the variance in the NOSQ is inherited than other affective-oriented dispositions.

An implication of the current study is that the NOSQ may be more affectiveoriented than other common affective-oriented dispositions and thus a valuable measurement tool in disposition research. Support for this argument is provided in the current study because the NOSQ correlated fewer times with cognitive-oriented dispositions than both PA and NA. Additional support for this claim can be found by comparing the format of the NOSQ to other disposition measures. More specifically, measures of PA and NA assume a respondent can accurately recall previous experiences of affect over extended periods of time (e.g., six months; Watson, Clark, \& Tellegen, 1988). Several concerns arise with this assumption. For example, when respondents are instructed to report their aggregated "general" affective states, as in measures of PA and NA, they engage in semantic memory recall (Robinson \& Clore, 2002). When respondents are instructed to report affective experiences at that moment or over a short period of time, as in the NOSQ, they engage in episodic memory recall. Whereas episodic memory is based on the actual affective experience, semantic memory is based on the beliefs about affective experiences. In addition, previous researchers have argued that retrospective reports of affect are primarily assessing the most intense and recent experiences of affect (Kahneman, 1999), or that retrospective reports are only assessing 
inferences about past feelings (Ross, 1989). In sum, survey respondents may engage in few cognitive processes when completing the NOSQ because the measure does not rely on a retrospective report of affect.

The format of the NOSQ may also be an indication that it is a more accurate assessment of affective-oriented content domain than other disposition measures. Whereas measures of PA and NA instruct respondents to report their tendency to experience an affective state, the NOSQ assesses affective tendencies toward objects. Reports of affective states, rather than affective tendencies toward objects, provides respondents with no reference to pull information from and thus limits the ability of the respondent to provide an accurate report. The presentation of an object allows the respondent to recall their overt behavior to the object, the appraisal of the object, the affective feeling, and the underlying neurophysiological activities (Barrett \& Russell, 1999). As a result, the NOSQ may provide a more accurate assessment of the intended affective-oriented construct than other disposition measures.

In addition to the evidence suggesting the NOSQ to be more affective-oriented than other affective-oriented disposition measures, future research should examine the likelihood of respondents to provide socially desirable responses to the NOSQ items. Social desirability is the need for social approval and the belief that engaging in socially acceptable behaviors can fulfill this need. People high in social desirability deny engaging in socially unacceptable behaviors and readily admit engaging in desirable behaviors (Chen, Dai, Spector, \& Jex, 1997). Previous research on social desirability and affective-oriented dispositions have found that items from measures of PA are perceived as socially desirable, whereas NA items are perceived as socially undesirable; thus, 
participant responses to positive and negative affectivity items will vary due to social desirability (Chen, et al., 1997). Although no previous study has directly compared social desirability and the NOSQ, Erez, Johnson, and Judge (1995) report correlations of selfdeception with PA, NA, and the NOSQ. The correlations indicate that the NOSQ has a weaker relationship with self-deception $(r=.26)$ than either PA $(r=.49)$ or NA $(r=.40)$. These results are an indication that the NOSQ would be weakly related with social desirability.

This empirical evidence is also supported by the design of the NOSQ. The PANAS provides the respondent with a stem item that is personally relevant and affective-oriented, whereas the stem item of the NOSQ is an item external of the individual. As a result, a participant is likely to detach themselves from the questions on the NOSQ and find the items less relevant to social acceptance. For example, a respondent may not understand why a researcher is asking about a "piece of paper" and would view feelings about the item as neither socially acceptable nor unacceptable. If an item is personally relevant, cognitive processes, involving motivational strategies, are likely to occur during information recall (Forgas, 1995). In addition, Larson, Diener, and Cropanzano (1987) find that affective stimuli evoke cognitive processes of personalization and generalization, whereas neutral stimuli did not. Therefore, the presentation of a neutral stem item on a survey may provide a more accurate and direct information recall of the disposition intended to be assessed. Future studies should examine whether the NOSQ items are perceived as desirable, undesirable, or neither. In addition, comparing these results with other affective-oriented measures could provide 
additional evidence that the NOSQ is assessing an affective-oriented construct that is contaminated by fewer cognitive processes than other affective-oriented measures. A final suggestion for future research involving the NOSQ pertains to continuing the development of the measure. Although Judge and Bretz (1993) adapted the measure to include more modern terminology and eliminate some items that were obviously less neutral (e.g., your last job), very little scale development has taken place since. Future research should examine if all items on the NOSQ are neutral and lack an affective orientation. Although the NOSQ loads onto a single factor, some items may be less neutral than others. For example, it is unlikely for a person to have a neutral response to “the way [he or she] was raised." In contrast, it is unlikely for a person to have any positive or negative experiences that are attributed to an "8 $1 \frac{1}{2}$ " by 11 " piece of paper." Positive items will likely be rated as satisfactory despite some respondents having a disposition to be dissatisfied. As a result, the less neutral items limit a researchers ability to infer dispositional tendencies. The varying degree of neutrality amongst the NOSQ items may explain why Judge and Bretz find that the items that are arguably the most neutral (e.g., piece of paper) have the weakest factor loadings. Although Judge and Hulin (1993) note that some items on the NOSQ are more neutral than others, researchers are yet to develop a revised version of the NOSQ in which new, more neutral items, are added to the scale. A revised, more neutral, version of the NOSQ is more consistent with the construct Weitz was trying to measure. As a result, a list of more neutral items on the NOSQ will likely provide a more accurate assessment of the intended disposition, reduce the effect of social desirability, and increase the amount of unique variance explained in affective-oriented variables. 
In addition to the development of a more neutral list of items, alternative versions of the NOSQ may need to be developed for different cultures. It is likely that items will be perceived as neutral and endemic to everyday life in one culture and affective-oriented or unfamiliar in another culture. Future researchers should consider the culture prior to administering the NOSQ and develop a culture specific NOSQ if needed.

\section{Limitations}

The current study is limited in several regards and, if possible, future studies should attempt to account for these limitations. As noted in the aforementioned discussion, the current study was unable to be conducted longitudinally. Thus, the study is unable to provide additional support for the stability of the NOSQ. Additional concerns are in regards to the lack of support for Hypothesis $3 \mathrm{~b}$. One potential explanation is that the job satisfaction measure used was not affective-oriented. Future studies should consider the inclusion of the Faces Scale for job satisfaction because of the affectiveorientation of the measure (Brief \& Roberson, 1989). A second explanation discussed was the use of a student sample. The sample is unlikely to have an effect when assessing stable dispositions, but is an area of concern for assessing relationships that include job attitudes.

Common-method bias is an additional concern for the current study. The bias provides an alternative explanation for a correlation between measures of different constructs (Podsakoff, MacKenzie, Lee, \& Podsakoff, 2003). Podsakoff and colleagues argue that if measures of two constructs share common methods, then a systematic effect will take place on the observed correlation. Common methods include collecting data from a common source or rater, item characteristics, and measurement context. Examples 
of common source biases, that may produce relationships that otherwise would not be found, include the following: an respondent's desire to appear consistent in their responses across all measures, a desire by the respondent to provide socially desirable responses, and a tendency to agree to items regardless of content. Item characteristic biases include item ambiguity, priming effects, and scale length. Lastly, measurement context effects include time, location, and what media researchers use to measure the constructs (Podsakoff et al., 2003).

Although common-method bias can be a problem in research, researchers may be overstating the issue (Spector, 2006). Spector argues that if common method bias is a widespread issue that has an effect on almost every study, researchers should find more significant correlations between variables. Spector provides evidence that common method bias is not as widespread as it appears. In addition, the current study limits the potential biases by using preexisting measures (item characteristic effects), consistent administration of the survey (context effects), and the survey design (e.g., priming effect and survey length) were carefully considered.

A potential concern for this study is that the dispositions chosen to represent the cognitive-oriented dispositions do not strongly correlate with the NOSQ for reasons other than cognition versus affect. Need for cognition, for example, did not correlate with the NOSQ. As a result, the eight comparisons involving the NOSQ and need for cognition yield stronger correlations with the affective-oriented disposition. Although the correlation for need for cognition stands out amongst the other correlations, it should not be cause for alarm. Need for cognition is defined as a cognitive-oriented disposition and does not conceptually overlap with the NOSQ construct. In addition, empirical support 
for the cognitive-orientation of need for cognition was found by having stronger correlations with self-efficacy and locus of control than with any affective-oriented disposition. The array of cognitive-oriented and affective-oriented dispositions should be viewed as a strength of the study and not a limitation.

A final limitation includes the difficulty to distinguish between affect and cognition using self-reports. Specifically, the study is based upon the theory that affect and cognition are distinct processes (Zajonc, 1980) and the assumption that self-reports can detect this distinction. It is not recommended to consider the NOSQ as a purely affective measure. It is likely that the NOSQ assesses some cognitive processes. Although support is found for the affective-orientation of the NOSQ, the difficulty to distinguish between affect and cognition should be considered a limitation to the design the current study.

\section{Conclusion}

The application and development of measures assessing affective-oriented dispositions should not be static, but rather consistently attempting to improve and gain insight on the effect of dispositions on organizational variables. An over-dependence on one construct to assess affective-oriented dispositions could limit the findings of the true underlying relationship (Brief, 2001). The current study addresses the concerns of previous researchers on the affective-orientation of the NOSQ (e.g., Fortunato \& Goldblatt, 2002) and enables future researchers to be confident in including the NOSQ as an affective-oriented dispositional measure. In addition, evidence is provided for the utility of the NOSQ in explaining unique variation in job attitudes when both affective and cognitive-oriented dispositions are controlled. Future research should continue to 
develop the nomological net of the NOSQ and researchers should be more willing to include the measure, most notably as a control variable, when assessing affectiveoriented variables, such as job or life attitudes. 


\section{References}

Arvey, R.D., Couchard, T. J., Segal, N. L., \& Abraja, L. M. (1989). Job satisfaction: Environmental and genetic components. Journal of Applied Psychology, 74, 187192.

Arvey, R.D., McCall, B. P., Bouchard, T. J., Taubman, P., \& Cavanaugh, M. A. (1993). Genetic influences on job satisfaction and work value. Personality and Individual Differences, 17, 21-33.

Ashton, M. C. (1998) Personality and job performance: the importance of narrow traits. Journal of Organizational Behavior, 19, 289-303.

Bandura, A. (1986). Social foundation of thought and action: A social-cognitive view. Englewood Cliffs, NJ: Prentice-Hall.

Barrett L. F., \& Russell, J. A. (1999). The structure of current affect: controversies and emerging consensus. American Psychological Society, 8, 10-14.

Beck A. T., Brown, G., Steer, R. A., Eidelson, J. I., \& Riskind, J. H. (1987). Differentiating anxiety and depression: a test of cognitive content-specificity hypothesis. Journal of Abnormal Psychology, 96, 179-183.

Bowling, N. A., \& Hammond, G. (2008). A meta-analytic examination of the construct validity of the Michigan Organizational Assessment Questionnaire Job Satisfaction Subscale. Journal of Vocational Behavior, 73, 63-77.

Brief, A. P., \& Roberson, L. (1989). Job attitude organization: an exploratory study. Journal of Applied Social Psychology, 19, 717-727.

Brief, A. P. (1998). Attitudes In and Around Organizations. Thousand Oaks, CA: Sage Publications. 
Burke, M. J., Brief, A. P., \& George, J. M. (1993). The role of negative affectivity in understanding relationships between self-reports of stressors and strains: A comment on the organizational literature. Journal of Applied Psychology, 78, 402412.

Cacioppo, J. T., \& Petty, R. E. (1982). The need for cognition. Journal of Personality and Social Psychology, 42, 116-131.

Cacioppo, J. T., Petty, R. E., Feinstein, J. A., \& Jarvis, B. G. (1996). Dispositional differences in cognitive motivation: the life and times of individuals varying in need for cognition. Psychological Bulletin, 119, 197-253.

Cammann, C., Fichman, M., Jenkins, G. D., \& Klesh, J. R. (1983). Assessing the attitudes and perceptions of organizational members. In Seashore, S. E., Lawler, E. E., Mirvis, P. H., \& Cammann, C. (eds.), Assessing Organizational Change. Wiley, New York.

Carter, S. D. (2004). Reexamining the temporal aspects of affect: relationships between repeatedly measured affective state, subjective well-being, and affective disposition. Personality and Individual Differences, 36, 381-391.

Chen, G., Gully, S. M., \& Eden, D. (2001). Validation of a new general self-efficacy scale. Organizational Research Methods, 4, 62-83.

Clark, D. A., Beck, A. T., \& Stewart, B. (1990). Cognitive specificity and positivenegative affectivity: complementary or contradictory views on anxiety and Depression? Journal of Abnormal Psychology, 99, 148-155. 
Clark, D. A., Steer, R. A., \& Beck, A. T. (1994). Common and specific dimensions of self-reported anxiety and depression: implications for cognitive and tripartite models. Journal of Abnormal Psychology, 103, 645-654.

Clark, L. A., \& Watson, D. (1991). Tripartite model of anxiety and depression: psychometric evidence and taxonomic implications. Journal of Abnormal Psychology, 100, 316-336.

Connolly, J. J., \& Viswesvaran, C. (1999). The independence of positive and negative affect: A met-analysis. Paper presented at Annual Meeting of the Society for Industrial and Organizational Psychology. Atlanta, GA.

Connolly, J. J., \& Viswesvaran, C. (2000). The role of affectivity in job satisfaction: a meta-analysis. Personality and Individual Differences, 29, 265-281.

Cooper, E. A., \& Scholl, R. W. (1989). Reliability of job evaluation: differences across sex-typed jobs. Journal of Business and Psychology, 4, 155-165.

Costa, P. T. Jr., \& McCrae, R. R. (1980). Influence of extraversion and neuroticism on subjective well-being: happy and unhappy people. Journal of Personality and Social Psychology, 38, 668-678.

Costa, P. T. Jr., \& McCrae, R. R. (1994). Set like plaster? Evidence for the stability of adult personality. In T. F. Heatherton \& J. L. Weinberger (Eds.), Can personality change? (pp. 21-40). Washington, DC: American Psychological Association.

Costa, P. T. Jr., \& McCrae, R. R. (1995). Domains and facets: hierarchical personality assessment using the revised NEO Personality Inventory. Journal of Personality Assessment, 64, 21-50. 
Cronbach, L., \& Meehl, P. (1955). Construct validity in psychological tests, Psychological Bulletin, 52, 281-302.

Cropanzano, R. Weiss, H. M., Hale, J., \& Reb, J. (2003). The structure of affect: reconsidering the relationship between negative and positive affectivity. Journal of Management, 29, 831-857.

Dalal, R. S. (2005). A meta-analysis of the relationship between organizational citizenship behavior and counterproductive work behavior. Journal of Applied Psychology, 90, 1241-1255.

Davis-Blake, A. \& Pfeffer, J. (1989) Just a mirage: the search for dispositional effects in organizational research. Academy of Management Review, 14, 385-400.

Deffenbacher, J. L. (1992). Trait anger: Theory, findings, and implications. In: Spielberger, C. B. and Butcher, J. N. (Eds) Advances in Personality Assessment, Vol. 9, Lawrence Erlbaum Associates, Hillsdale, NH, 177-201.

Diener, E. (1984). Subjective well-being. Psychological Bulletin, 95, 542-575.

Diener, E., \& Emmons, R. A. (1984). The independence of positive and negative affect. Journal of Personality and Social Psychology, 47, 1105-1117.

Dormann, C., \& Zapf, D. (2001). Job satisfaction: a meta-analysis of stabilities. Journal of Organizational Behavior, 22, 483-504.

Emmons, R. A., \& Diener, E. (1985). Personality correlates of subjective well-being. Personality and Social Psychology Bulletin, 11, 89-97.

Emmons, R. A., \& Diener, E. (1986). Influence of impulsivity and sociability on subjective well-being. Journal of Personality and Social Psychology, 50, 12111215. 
Erez, A., \& Judge, T. A. (1994). Dispositional source of job satisfaction: The role of selfdeception. Unpublished manuscript.

Eschleman, K. J, \& Bowling, N. A (2008). A meta-analysis of the Neutral Objects Satisfaction Questionnaire (NOSQ). Unpublished manuscript.

Forgas, J. P., (1995). Mood and judgment: the affect infusion model (AIM). Psychological Bulletin, 17, 39-66.

Fortunato, V. J. \& Goldblatt, A. M. (2002). Construct validation of a revised strain-free negative affectivity scale. Educational and Psychological Measurement, 62, 4563.

Fox, S \& Spector, P. E. (1999). A model of work frustration-aggression. Journal of Organizational Behavior, 20, 915-931.

Gerhart, B. (1987). How important are dispositional factors as determinants of job satisfaction? Implications for job design and other personnel programs. Journal of Applied Psychology, 72, 336-373.

Gerhart, B. (2005). The (affective) dispositional approach to job satisfaction: sorting out the policy implications. Journal of Organizational Behavior, 26, 79-97.

Hackman, J.R., \& Oldham, G. R. 1976. Motivation through the design of work: Test of a theory. Organizational Behavior and Human Performance, 16, 250-279.

Hellman, C. M. (1997). Job Satisfaction and intent to leave. Journal of Social Psychology, 137, 677-689.

Hitlan, R. T., Cliffton, R. J., \& DeSoto, M. C. (2006). Perceived exclusion in the workplace: the moderating effects of gender on the work-related attitudes and psychological health. North American Journal of Psychology, 8, 217-236. 
House, R. J., Shane, S. A., \& Herold, D. M. (1996). Rumors of the death of dispositional research are vastly exaggerated. Academy of Management Review, 21, 203-224.

International Personality Item Pool (2001). A scientific collaboratory for the development of advanced measures of personality traits and other individual differences. Retrieved January 15, 2007, Available from http://ipip.ori.org/.

Ilies, R., \& Judge, T. A. (2003). On the heritability of job satisfaction: the mediating role of personality. Journal of Applied Psychology, 89, 750-759.

Judge, T. A., \& Bono, J. E. (2001a). Relationship of core self-evaluations traits- selfesteem, generalized self-efficacy, locus of control, and emotional stability- with job satisfaction and job performance: a meta-analysis. Journal of Applied Psychology, 86, 80-92.

Judge, T. A., \& Bono, J. E. (2001b). Are self-esteem, generalized self-efficacy, neuroticism, and locus of control indicators of a common construct? In R. Hogan, Personality Psychology in the Workplace (pp. 93-118). Washington D.C.: American Psychology Association.

Judge, T. A., Bono, J. E., Joyce, E., \& Thoresen, C. (2002). Are measures of self-esteem, neuroticism, locus of control, and generalized self-efficacy indicators of a common core construct? Journal of Personality and Social Psychology, 83, 693710.

Judge, T. A., \& Bretz, R. D. (1993). Report on an alternative measure of affective disposition. Educational and Psychological Measurement, 53, 1095-1104. 
Judge, T. A., Heller, D., \& Mount, M. K. (2002). Five-factor model of personality and job satisfaction: a meta-analysis. Organizational Behavior and Human Decision Process, 86, 67-98.

Judge, T. A., \& Higgins, C. A. (1998). Affective disposition and the letter of reference. Organizational Behavior and Human Decision Processes, 75, 207-221.

Judge, T. A., \& Hulin, C. L. (1993). Job satisfaction as a reflection of disposition: A multiple source causal analysis. Organizational Behavior and Human Decision Processes, 56, 388-421.

Judge, T. A. (1993). Does affective disposition moderate the relationship between job satisfaction and voluntary turnover? Journal of Applied Psychology, 78, 395-401.

Judge, T. A., \& Larson, R. J. (2001). Dispositional affect and job satisfaction: A review and theoretical extension. Organizational Behavior and Human Decision Processes, 86, 67-98.

Judge, T. A., \& Locke, E. A. (1993). Effect of dysfunctional thought processes on subjective well-being and job satisfaction. Journal of Applied Psychology, 78, $475-490$.

Judge, T. A., Locke, E. A., Durham, C. C., \& Kluger, A. N. (1998). Dispositional effects on job and life satisfaction: The role of core evaluations. Journal of Applied Psychology, 83, 17-34.

Kahneman, D. (1999). Objective happiness. In D. Kahneman, E. Diener, \& N, Schwarz (Eds.), Well-being: The foundations of hedonic psychology (pp. 85-105). New York: Russell Sage Foundation. 
LePine, J. A., \& Johnson, D. E. (2002). The nature and dimensionality of organizational citizenship behavior: A critical review and meta-analysis. Journal of Applied Psychology, 87(1), 52-65.

Levenson, H. (1981). Research with the locus of control construct. New York: Academic Press.

MacLeod, C., Rutherford, E. M., Campbell, L., \& Ebsworthy, G., Holker, L. (2002). Selective attention and emotional vulnerability: assessing the causal basis of their association through the experimental manipulation of attentional bias. Journal of Abnormal Psychology, 111, 107-123.

MacLeod, C., \& Rutherford, E. M. (1998). Automatic and strategic cognitive biases in anxiety and depression. In K. Kirsner, C. Speelman, M. Maybery, A. O’BrienMalone, M. Anderson, \& C. MacLeod (Eds.), Implicit and Explicit Mental Processes (pp. 233-254). Mahwah, NJ: Erlbaum.

Mastrangelo, P. M., Guy, J. L., Greenamayer, C. J., \& Melanson, K. M. (1997). The role of job importance in the life - job satisfaction relationship. A presentation at the Twelfth Annual Conference of the Society for Industrial and Organizational Psychology, St. Louis, MO.

Mathews, A., \& MacLeod, C. (1994). Cognitive approaches to emotion and emotional disorders. Annual Review of Psychology, 45, 25-50.

McCrae, R. R., Costa, JR., P. T. (1992). Discriminant validity of NEO-PIR facet scales. Educational and Psychological Measurement, 52, 229-237. 
Mischel, W., \& Shoda, Y. (1995). A cognitive-affective system theory of personality: reconceptualizing situations, dispositions, dynamics, and invariance in personality structure. Psychological Review, 102, 246-268.

Mitchell, T. R., Hopper, H. Daniels, D., George-Falvy, J. \& James, L. R. (1994). Predicting self-efficacy and performance during skill acquisition. Journal of Applied Psychology, 79, 506-517.

Olsen, J. M., \& Zanna, M. P. (1993). Attitudes and attitude change. Annual Review of Psychology, 44, 117-154.

Organ, D. W. \& Konovsky, M. (1989). Cognitive versus affective determinants of organizational citizenship behavior. Journal of Applied Psychology, 74, 157-164.

Organ, D. W., \& Near, J. P. (1985). Cognition vs. affect in measures of job satisfaction. International Journal of Psychology, 20, 241-253.

Petty, R. E., Weneger, D. T., \& Fabrigar, L. R. (1997). Attitudes and attitude change. Annual Review of Psychology, 48, 609-647.

Piccolo, R. F., Judge, T. A., Takahashi, K., Watanabe, N., \& Locke, E. A. (2005). Core self-evaluations in Japan: relative effects on job satisfaction, life satisfaction, and happiness. Journal of Organizational Behavior, 26, 965-984.

Probst, T. M. (2003). Development and validation of the Job Security Index and the Job Security Satisfaction scale: a classical test theory of the IRT approach. Journal of Occupational and Organizational Psychology, 76, 451-467.

Robinson, M. D., \& Clore, G. L. 2002. Belief and feeling: Evidence for an accessibility model of emotional self report. Psychological Bulletin, 128, 934-960.

Ross, M. (1989). The relation of implicit theories to the construction of personal histories. Psychological Review, 103, 734-760. 
Rotter, J. B. (1966). Generalized expectancies for internal versus external control of reinforcement. Psychological Monographs, 80, 1-28.

Roy, M. Neale, M. C., \& Kendler, K. S. (1995). The genetic epidemiology of self-esteem. British Journal of Psychiatry, 166, 813-820.

Ruch, W., Kohler, G., \& Van Thriel, C. (1997). To be in good or bad humor: construction of the state form of the State-Trait-Cheerfulness-Inventory-STCI. Personality and Individual Differences, 22, 477-491.

Russell, J. A., \& Barrett, L. F. (1999). Core affect, prototypical emotional episodes, and other things called emotion: dissecting the elephant. Journal of Personality and Social Psychology, 76, 805-819.

Russell, J. A., \& Carroll, J. M. (1999). On the bipolarity of positive and negative affect: Rumors of its death are greatly exaggerated. Psychological Bulletin, 125, 3-30.

Scheier, M. F., Carver, C. S., \& Bridges, M. W. (1994). Distinguishing optimism from neuroticism (and trait anxiety, self-mastery, and self-esteem): A reevaluation of the Life Orientation Test. Journal of Personality and Social Psychology, 67, 1063-1078.

Schneider, K. T., Hitlan, R. T., \& Radhakrishnan, P. (2000). An examination of the nature and correlates of ethnic harassment experiences in multiple contexts. Journal of Applied Psychology, 85, 3-12.

Schneider, R. J., Hough, L. M., \& Dunnette, M. D. (1996). Broadsided by broad traits: how to sink science in five dimensions or less. Journal of organizational Behavior, 17, 639-655. 
Scholl, R. W., Cooper, E. A., \& McKenna, J. F. (1987). Referent selection in determining equity perceptions: differential effects on behavioral and attitudinal outcomes. Personnel Psychology, 40, 113-124.

Sinclair, R. C., Mark, M. M., Enzle, M. E., Borkovec, T. D., \& Cumbleton, A. G. (1994). Toward a multiple-method view of mood induction: The appropriateness of a modified velten mood induction technique and the problems of procedures with group assignment to conditions. Basic Applied Social Psychology, 15, 389-408.

Spector, P. E. (1997). Job Satisfaction. Thousand Oaks, CA: Sage.

Spector, P. E., Fox, S., \& Van Katwyk, P. T. (1999). The role of negative affectivity in employee reactions to job characteristics: Bias effect or substantive effect? Journal of Occupational and Organizational Psychology, 72, 205-218.

Spector, P. E., Jex, S. M., \& Chen, P. Y. (1995). Relations of incumbent affect-related personality traits with incumbent and objective measures of characteristics of jobs. Journal of Organizational Behavior, 16, 59-65.

Spector, P. E., Zapf, D., Chen, P. Y., \& Frese, M. (2000). Why negative affectivity should not be controlled in job stress research: Don't throw out the baby with the bath water. Journal of Occupational Behavior, 21, 79-95.

Spielberger, C. D., Krasner, S. S., \& Solomon, E. P. (1988). The experience, expression, and control of anger. In: Janisse, M. P. (Ed.) Health Psychology: Individual Differences, Diagnosis, and Treatment, Taylor \& Francis, Washington, DC.

Spielberger, C. D., \& Syderman, S. J. (1994). State-trait anxiety inventory and state-trait expression inventory. In: Maruish, M. E. (Ed.) The Use of Psychological Tests for Treatment Planning and Outcome Assessment, LEA, Hillsdale, NJ. 
Staw, B. M., Bell, N. E., \& Clausen, J. A. (1986). The dispositional approach to job attitudes: a lifetime longitudinal test. Administrative Science Quarterly, 31, 56-77.

Staw, B. M., \& Ross, J. (1985). Stability in the midst of change: a dispositional approach to job attitudes. Journal of Applied Psychology, 70, 469-480.

Staw, B. M., \& Cohn-Charash, Y. (2005). The dispositional approach to job satisfaction: more than a mirage, but not yet an oasis. Journal of Organizational Behavior, 26, $59-78$.

Suls, J., \& Bunde, J. (2004). Anger, anxiety, and depression as risk factors for cardiovascular disease: the problems and implications of overlapping affective dispositions. Psychological Bulletin, 131, 260-300.

Tett, B. P., Steele, J. R., \& Beauregard, R. S. (2003). Broad and narrow measures on both sides of the personality-job performance relationship. Journal of Organizational Behavior, 24, 335-356.

Thoreson, C. J., Kaplan, S. A., Barsky, A. P., Warren, C. R., \& Chermont, K. (2003). The affective underpinnings of job perceptions and attitudes: a meta-analytic review and integration. Psychological Bulletin, 129, 914-945.

Turvey, M. T. (1973). On peripheral and central processes in vision: inferences from an information-processing analysis of masking patterned stimuli. Psychological Review, 80, 1-52.

Van Katwyk, P. T., Fox, S., Spector, P. E., \& Kelloway, K. E. (2000). Using the JobRelated Affective Well-Being Scale (JAWS) to investigate affective responses to work stressors. Journal of Occupational Health Psychology, 5, 219-230. 
Watson, D., \& Tellegen, A. (1985). Toward a consensual structure of mood. Psychological Bulletin, 98, 219-235.

Watson, D., \& Clark, L. A. (1984). Negative affectivity: the disposition to experience aversive emotional states. Psychological Bulletin, 96, 465-490.

Watson, D., Clark, L. A. (1992). On traits and temperament: general and specific factors of emotional experience and the relation to the five-factor model. Journal of Personality, 60, 441-476.

Watson, D., Clark, L. A., \& Tellegen, A. (1988). Development and validation of brief measures of positive and negative affect: The PANAS scales. Journal of Personality and Social Psychology, 54, 1063-1070.

Watson, D., Clark, L. A., McIntyre. C. W., \& Hamaker, S. (1992). Affect, personality, and social activity. Journal of Personality and Social Psychology, 54, 1063-1070.

Watson, D., \& Tellegen, A. (1985). Toward a consensual structure of mood. Psychological Bulletin, 98, 219-235.

Wegge, J., Van Dick, R., Gisher, G. K., West, M. A., \& Dawson, J. F. (2006). A test of basic assumptions of Affective Events Theory (AET) in call centre work. British Journal of Management, 17, 237-254.

Weiss, H. M., \& Cropanzano, R. (1996). Affective events theory: a theoretical discussion of the structure, causes, and consequences of affective experiences at work. Research in Organizational Behavior, 18, 1-74.

Weiss, H. M. (1996). Affective events theory: A theoretical discussion of the structure, causes and consequences of affective experiences and job beliefs on job 
satisfaction and variations in affective experiences over time. Research in Organizational Behavior, 18, 1-74.

Weiss, H. M. (2002). Deconstructing job satisfaction: Separating evaluations, beliefs and affective experiences. Human Resource Management Review, 12, 173-194.

Weitz, J. (1952). A neglected concept in the study of job satisfaction. Personnel Psychology, 5, 201-205.

Zajonc, R. B. (1980). Feeling and thinking preferences need no inferences. American Psychologist, 35, 151-175.

Zickar, M. J., Gibby, R. E., \& Jenny, T. (2003). Job attitudes of workers with two jobs. Journal of Vocational Behavior, 64, 222-235. 
Table 1

Descriptive Statistics, Reliabilities, and Correlations for Study Variables

\begin{tabular}{|c|c|c|c|c|c|c|c|c|c|c|c|}
\hline & $\mathrm{N}$ & Mean & SD & 1 & 2 & 3 & 4 & 5 & 6 & 7 & 8 \\
\hline $1 \mathrm{NOSQ}$ & 396 & 2.41 & 0.29 & $(.83)$ & $.39 * *$ & $-.27 * *$ & $-.26 * *$ & $-.40 * *$ & $-.27 * *$ & $.37 * *$ & $-.37 * *$ \\
\hline $2 \mathrm{PA}$ & 395 & 3.84 & 0.49 & $.32 * *$ & $(.81)$ & $-.43 * *$ & $-.53 * *$ & $-.64 * *$ & $-.42 * *$ & $.56^{* *}$ & $-.61 * *$ \\
\hline $3 \mathrm{NA}$ & 396 & 2.39 & 0.52 & $-.22 * *$ & $-.35 * *$ & $(.81)$ & $.81^{* *}$ & $.81 * *$ & $.71 * *$ & $-.34 * *$ & $.88 * *$ \\
\hline 4 Anxiety & 395 & 2.82 & 0.59 & $-.21 * *$ & $-.42 * *$ & $.65 * *$ & $(.79)$ & $.79 * *$ & $.78 * *$ & $-.38 * *$ & $.97 * *$ \\
\hline 5 Depression & 395 & 2.26 & 0.65 & $-.34 * *$ & $-.53 * *$ & $.67 * *$ & $.65^{* *}$ & $(.85)$ & $.69 * *$ & $-.58 * *$ & $1.00 * *$ \\
\hline 6 Anger & 396 & 2.67 & 0.69 & $-.23 * *$ & $-.35^{* *}$ & $.60 * *$ & $.65^{* *}$ & $.59 * *$ & $(.87)$ & $-.37 * *$ & $.89 * *$ \\
\hline 7 Cheerfulness & 395 & 3.80 & 0.50 & $.29 * *$ & $.43^{* *}$ & $-.26 * *$ & $-.29 * *$ & $-.46^{* *}$ & $-.30 * *$ & $(.74)$ & $-0.53 * *$ \\
\hline 8 Neuroticism & 396 & 2.44 & 0.60 & $-.30 * *$ & $-.49 * *$ & $.71 * *$ & $.77 * *$ & $.90 * *$ & $.74 * *$ & $-.41 * *$ & $(.80)$ \\
\hline 9 Extraversion & 395 & 3.60 & 0.59 & $.22 * *$ & $.41 * *$ & $-.26 * *$ & $-.31 * *$ & $-.42 * *$ & $-.24 * *$ & $.55^{* *}$ & $-.37 * *$ \\
\hline 10 Locus of Control & 396 & 3.74 & 0.44 & $.22 * *$ & $.61 * *$ & $-.58 * *$ & $-.56 * *$ & $-.78 * *$ & $-.48 * *$ & $.42 * *$ & $-.68 * *$ \\
\hline 11 Need for Cognition & 395 & 3.41 & 0.56 & .00 & $.37 * *$ & $-.25 * *$ & $-.35 * *$ & $-.29 * *$ & $-.30 * *$ & $.22 * *$ & $-.31 * *$ \\
\hline 12 Self-efficacy & 395 & 3.87 & 0.53 & $.20 * *$ & $.62 * *$ & $-.35 * *$ & $-.43 * *$ & $-.53 * *$ & $-.33 * *$ & $.41 * *$ & $-.47 * *$ \\
\hline 13 Job Satisfaction & 317 & 3.67 & 0.96 & $.19 * *$ & $.27 * *$ & $-.11 *$ & -.10 & $-.16^{* *}$ & -.04 & .10 & $-.12 *$ \\
\hline 14 Job Cognitions & 317 & 3.63 & 0.66 & $.22 * *$ & $.32 * *$ & -.04 & -.06 & $-.16^{* *}$ & .01 & $.16^{* *}$ & -.08 \\
\hline 15 Mood & 392 & 4.55 & 1.05 & $.16^{* *}$ & $.31 * *$ & $-.23 * *$ & $-.25 * *$ & $-.32 * *$ & $-.26^{* *}$ & $.26 * *$ & $-.32 * *$ \\
\hline 16 Age & 395 & 19.17 & 2.26 & -.09 & $.10^{*}$ & -.09 & $-.13^{*}$ & -.06 & -.08 & -.06 & -.06 \\
\hline 17 Tenure & 317 & 20.57 & 12.14 & .04 & .06 & -.03 & -.04 & -.01 & -.10 & .01 & -.04 \\
\hline 18 Hours Per Week & 317 & 25.73 & 6.2 & -.02 & .07 & -.03 & -.09 & -.03 & -.04 & .00 & -.04 \\
\hline 19 Ethnicity & 393 & 1.36 & .48 & .00 & $.13 * *$ & -.06 & $-.12 *$ & $-.12 *$ & -.01 & $-.12 *$ & -.10 \\
\hline 20 Gender & 390 & 1.30 & .46 & -.06 & .01 & -.05 & $-.23 * *$ & .03 & -.07 & -.03 & -.07 \\
\hline
\end{tabular}

Note. Uncorrected correlations presented below the diagonal. Correlations corrected for unreliability presented above the diagonal. Alpha reliabilities are presented on the diagonal in parentheses. Ethnicity is coded as $1=$ Caucasian $2=$ other. Gender is coded as $1=$ female $2=$ male. ${ }^{*} \mathrm{p}<.05, * * \mathrm{p}<.01$. 
Table 1 continued

Descriptive Statistics and Correlation Matrix

\begin{tabular}{|c|c|c|c|c|c|c|c|c|c|c|c|c|}
\hline & 9 & 10 & 11 & 12 & 13 & 14 & 15 & 16 & 17 & 18 & 19 & 20 \\
\hline 1 NOSQ & $.27 * *$ & $.27 * *$ & .00 & $.24 * *$ & $.22 * *$ & $.27 * *$ & $.21 * *$ & .04 & .04 & -.02 & .00 & -.06 \\
\hline $2 \mathrm{PA}$ & $.51 * *$ & $.75 * *$ & $.47 * *$ & $.76^{* *}$ & $.31 * *$ & $.39 * *$ & $.41 * *$ & $.10^{*}$ & .06 & .07 & $.13 * *$ & .01 \\
\hline $3 \mathrm{NA}$ & $-.32 * *$ & $-.71 * *$ & $-.31 * *$ & $-.43 * *$ & $-.13 *$ & -.05 & $-.30 * *$ & -.09 & -.03 & -.03 & -.06 & -.05 \\
\hline 4 Anxiety & $-.39 * *$ & $-.70 * *$ & $-.45 * *$ & $-.53 * *$ & -.12 & -.07 & $-.33 * *$ & $-.13 *$ & -.04 & -.09 & $-.12 *$ & $-.23 * *$ \\
\hline 5 Depression & $-.51 * *$ & $-.93 * *$ & $-.36 * *$ & $-.63 * *$ & $-.18 * *$ & $-.19 * *$ & $-.41 * *$ & -.06 & -.01 & -.03 & $-.12 *$ & .03 \\
\hline 6 Anger & $-.29 * *$ & $-.57 * *$ & $-.36 * *$ & $-.39 * *$ & -.04 & .01 & $-.33 * *$ & -.08 & -.10 & -.04 & -.01 & -.07 \\
\hline 7 Cheerfulness & $.71 * *$ & $.54 * *$ & $.29 * *$ & $.52 * *$ & .12 & $.20 * *$ & $.36 * *$ & -.06 & .01 & .00 & $-.12 *$ & -.03 \\
\hline 8 Neuroticism & $-.46 * *$ & $-.84 * *$ & $-.39 * *$ & $-.58 * *$ & $-.14 *$ & -.10 & $-.42 * *$ & -.06 & -.04 & -.04 & -.10 & -.07 \\
\hline 9 Extraversion & $(.81)$ & $.58 * *$ & $.28 * *$ & $.46^{* *}$ & .13 & $.21 * *$ & $.28 * *$ & -.03 & .07 & .11 & .00 & -.07 \\
\hline 10 Locus of Control & $.47 * *$ & $(.82)$ & $.55 * *$ & $.90 * *$ & $.15^{*}$ & $.24 * *$ & $.38 * *$ & .11 & .03 & .08 & $.12 *$ & -.06 \\
\hline 11 Need for Cognition & $.22 * *$ & $.44 * *$ & $(.78)$ & $.67 * *$ & -.05 & .05 & $.22 * *$ & $.12 *$ & $.12 *$ & .09 & .07 & .01 \\
\hline 12 Self-efficacy & $.38 * *$ & $.74 * *$ & $.54 * *$ & $(.83)$ & $.21 * *$ & $.30 * *$ & $.27 * *$ & $.10^{*}$ & .02 & $.11^{*}$ & .07 & -.04 \\
\hline 13 Job Satisfaction & .11 & $.13^{*}$ & -.04 & $.18^{* *}$ & $(.91)$ & $.69 * *$ & .12 & .08 & .02 & .01 & .08 & $-.15^{*}$ \\
\hline 14 Job Cognitions & $.17 * *$ & $.20 * *$ & .04 & $.25 * *$ & $.60 * *$ & $(.83)$ & $.20 * *$ & -.04 & .04 & .00 & .02 & $-.16^{* *}$ \\
\hline 15 Mood & $.21 * *$ & $.29 * *$ & $.16^{* *}$ & $.21 * *$ & .10 & $.15^{* *}$ & $(.71)$ & $.11^{*}$ & .17 & .10 & .03 & -.02 \\
\hline 16 Age & -.03 & .11 & $.12^{*}$ & $.10^{*}$ & .08 & -.04 & $.11^{*}$ & -- & $.35^{* *}$ & .11 & .05 & $.13^{*}$ \\
\hline 17 Tenure & .07 & .03 & $.12 *$ & .02 & .02 & .04 & $.17^{*}$ & $.35 * *$ & -- & .08 & -.10 & .02 \\
\hline 18 Hours Per Week & .11 & .08 & .09 & $.11 *$ & .01 & .00 & .10 & .11 & .08 & -- & -.01 & .00 \\
\hline 19 Ethnicity & .00 & $.12 *$ & .07 & .07 & .08 & .02 & .03 & .05 & -.10 & -.01 & -- & -.04 \\
\hline 20 Gender & -.07 & -.06 & .01 & -.04 & $-.15^{*}$ & $-.16^{* *}$ & -.02 & $.13 *$ & .02 & .00 & -.04 & -- \\
\hline
\end{tabular}

Note. Uncorrected correlations presented below the diagonal. Correlations corrected for unreliability presented above the diagonal. Alpha reliabilities are presented on the diagonal in parentheses. Ethnicity is coded as $1=$ Caucasian $2=$ other. Gender is coded as $1=$ female $2=$ male. $* \mathrm{p}<.05, * * \mathrm{p}<.01$. 
Table 2

Comparison of the Relationships Between the NOSQ and Affective-Oriented Dispositions with the Relationships Between the NOSQ and Cognitive-Oriented Dispositions

\begin{tabular}{|c|c|c|c|c|c|}
\hline & Correlations in Comparison & $N$ & First Correlation & Second Correlation & $t$ \\
\hline $\begin{array}{l}1 \mathrm{a} . \\
1 \mathrm{~b} .\end{array}$ & $\begin{array}{l}\text { Positive affectivity with the NOSQ } \\
\text { Locus of control with the NOSQ }\end{array}$ & 395 & $.32 * *$ & $.22 * *$ & 1.59 \\
\hline $\begin{array}{l}2 \mathrm{a} . \\
2 \mathrm{~b} .\end{array}$ & $\begin{array}{l}\text { Positive affectivity with the NOSQ } \\
\text { Need for cognition with the NOSQ }\end{array}$ & 395 & $.32 * *$ & .00 & $5.77 * *$ \\
\hline $\begin{array}{l}3 \mathrm{a} . \\
3 \mathrm{~b} .\end{array}$ & $\begin{array}{l}\text { Positive affectivity with the NOSQ } \\
\text { General self-efficacy with the NOSQ }\end{array}$ & 395 & $.32 * *$ & $.20 * *$ & $1.92 *$ \\
\hline $\begin{array}{l}4 \mathrm{a} . \\
4 \mathrm{~b} .\end{array}$ & $\begin{array}{l}\text { Negative affectivity with the NOSQ } \\
\text { Locus of control with the NOSQ }\end{array}$ & 396 & $-.22 * *$ & $.22 * *$ & 0.00 \\
\hline $\begin{array}{l}5 \mathrm{a} . \\
5 \mathrm{~b} .\end{array}$ & $\begin{array}{l}\text { Negative affectivity with the NOSQ } \\
\text { Need for cognition with the NOSQ }\end{array}$ & 395 & $-.22 * *$ & .00 & $3.58 * *$ \\
\hline $\begin{array}{l}6 \mathrm{a} . \\
6 \mathrm{~b} .\end{array}$ & $\begin{array}{l}\text { Negative affectivity with the NOSQ } \\
\text { General self-efficacy with the NOSQ }\end{array}$ & 395 & $-.22 * *$ & $.20 * *$ & 0.30 \\
\hline $\begin{array}{l}7 \mathrm{a} . \\
7 \mathrm{~b} .\end{array}$ & $\begin{array}{l}\text { Neuroticism with the NOSQ } \\
\text { Locus of control with the NOSQ }\end{array}$ & 396 & $-.30 * *$ & $.22 * *$ & 1.25 \\
\hline $\begin{array}{l}8 \mathrm{a} . \\
8 \mathrm{~b} .\end{array}$ & $\begin{array}{l}\text { Neuroticism with the NOSQ } \\
\text { Need for cognition with the NOSQ }\end{array}$ & 395 & $-.30^{* *}$ & .00 & $5.29 * *$ \\
\hline $\begin{array}{l}9 \mathrm{a} . \\
9 \mathrm{~b} .\end{array}$ & $\begin{array}{l}\text { Neuroticism with the NOSQ } \\
\text { General self-efficacy with the NOSQ }\end{array}$ & 395 & $-.30 * *$ & $.20 * *$ & 1.57 \\
\hline $\begin{array}{l}10 \mathrm{a} . \\
10 \mathrm{~b} .\end{array}$ & $\begin{array}{l}\text { Extraversion with the NOSQ } \\
\text { Locus of control with the NOSQ }\end{array}$ & 395 & $.22 * *$ & $.22 * *$ & 0.00 \\
\hline
\end{tabular}

Note. ${ }^{*} p<.05 ;{ }^{* *} p<.01$ 
Neutral Objects Satisfaction Questionnaire 64

Table 2 continued

Comparison of the Relationships Between the NOSQ and Affective-Oriented Dispositions with the Relationships Between the NOSQ and Cognitive-Oriented Dispositions

\begin{tabular}{|c|c|c|c|c|c|}
\hline & Correlations in Comparison & $N$ & First Correlation & Second Correlation & $t$ \\
\hline $\begin{array}{l}11 \mathrm{a} . \\
11 \mathrm{~b} .\end{array}$ & $\begin{array}{l}\text { Extraversion with the NOSQ } \\
\text { Need for cognition with the NOSQ }\end{array}$ & 395 & $.22 * *$ & .00 & $3.58 * *$ \\
\hline $\begin{array}{l}12 \mathrm{a} . \\
12 \mathrm{~b} .\end{array}$ & $\begin{array}{l}\text { Extraversion with the NOSQ } \\
\text { General self-efficacy with the NOSQ }\end{array}$ & 395 & $.22 * *$ & $.20 * *$ & 0.30 \\
\hline $\begin{array}{l}13 \mathrm{a} . \\
13 \mathrm{~b} .\end{array}$ & $\begin{array}{l}\text { Trait anxiety with the NOSQ } \\
\text { Locus of control with the NOSQ }\end{array}$ & 395 & $-.21 * *$ & $.22 * *$ & -0.15 \\
\hline $\begin{array}{l}14 \mathrm{a} . \\
14 \mathrm{~b} .\end{array}$ & $\begin{array}{l}\text { Trait anxiety with the NOSQ } \\
\text { Need for cognition with the NOSQ }\end{array}$ & 395 & $-.21 * *$ & .00 & $3.39 * *$ \\
\hline $\begin{array}{l}15 \mathrm{a} . \\
15 \mathrm{~b} .\end{array}$ & $\begin{array}{l}\text { Trait anxiety with the NOSQ } \\
\text { General self-efficacy with the NOSQ }\end{array}$ & 395 & $-.21 * *$ & $.20 * *$ & 0.15 \\
\hline $\begin{array}{l}16 \mathrm{a} . \\
16 \mathrm{~b} .\end{array}$ & $\begin{array}{l}\text { Trait anger with the NOSQ } \\
\text { Locus of control with the NOSQ }\end{array}$ & 396 & $-.23 * *$ & $.22 * *$ & 0.15 \\
\hline $\begin{array}{l}17 \mathrm{a} . \\
17 \mathrm{~b} .\end{array}$ & $\begin{array}{l}\text { Trait anger with the NOSQ } \\
\text { Need for cognition with the NOSQ }\end{array}$ & 395 & $-.23 * *$ & .00 & $3.78 * *$ \\
\hline $\begin{array}{l}18 \mathrm{a} . \\
18 \mathrm{~b} .\end{array}$ & $\begin{array}{l}\text { Trait anger with the NOSQ } \\
\text { General self-efficacy with the NOSQ }\end{array}$ & 395 & $-.23 * *$ & $.20 * *$ & 0.45 \\
\hline $\begin{array}{l}19 \mathrm{a} . \\
19 \mathrm{~b} .\end{array}$ & $\begin{array}{l}\text { Trait depression with the NOSQ } \\
\text { Locus of control with the NOSQ }\end{array}$ & 395 & $-.34 * *$ & $.22 * *$ & $2.01 * *$ \\
\hline $\begin{array}{l}20 \mathrm{a} . \\
20 \mathrm{~b}\end{array}$ & $\begin{array}{l}\text { Trait depression with the NOSQ } \\
\text { Need for cognition with the NOSQ }\end{array}$ & 395 & $-.34 * *$ & .00 & $6.28 * *$ \\
\hline
\end{tabular}

Note. ${ }^{*} p<.05 ; * * p<.01$ 


\section{Neutral Objects Satisfaction Questionnaire 65}

Table 2 continued

Comparison of the Relationships Between the NOSQ and Affective-Oriented Dispositions with the Relationships Between the NOSQ and Cognitive-Oriented Dispositions

\begin{tabular}{|c|c|c|c|c|c|}
\hline & Correlations in Comparison & $N$ & First Correlation & Second Correlation & $t$ \\
\hline $\begin{array}{l}21 \mathrm{a} . \\
21 \mathrm{~b} .\end{array}$ & $\begin{array}{l}\text { Trait depression with the NOSQ } \\
\text { General self-efficacy with the NOSQ }\end{array}$ & 395 & $-.34 * *$ & $.20 * *$ & $2.28 * *$ \\
\hline $\begin{array}{l}22 \mathrm{a} . \\
22 \mathrm{~b} .\end{array}$ & $\begin{array}{l}\text { Cheerfulness with the NOSQ } \\
\text { Locus of control with the NOSQ }\end{array}$ & 395 & $.29 * *$ & $.22 * *$ & 1.09 \\
\hline $\begin{array}{l}23 \mathrm{a} . \\
23 \mathrm{~b} .\end{array}$ & $\begin{array}{l}\text { Cheerfulness with the NOSQ } \\
\text { Need for cognition with the NOSQ }\end{array}$ & 395 & $.29 * *$ & .00 & $5.06^{* *}$ \\
\hline $\begin{array}{l}24 \mathrm{a} . \\
24 \mathrm{~b} .\end{array}$ & $\begin{array}{l}\text { Cheerfulness with the NOSQ } \\
\text { General self-efficacy with the NOSQ }\end{array}$ & 395 & $.29 * *$ & $.20 * *$ & 1.40 \\
\hline
\end{tabular}

Note. ${ }^{*} p<.05 ; * * p<.01$ 
Table 3

Comparison of the Relationships Between the NOSQ and Affective-Oriented Dispositions with the Relationships Between the NOSQ and Mood

\begin{tabular}{|c|c|c|c|c|c|}
\hline & Correlations in Comparison & $N$ & First Correlation & Second Correlation & $t$ \\
\hline $\begin{array}{l}1 \mathrm{a} . \\
1 \mathrm{~b} .\end{array}$ & $\begin{array}{l}\text { Positive affectivity with the NOSQ } \\
\text { Mood with the NOSQ }\end{array}$ & 392 & $0.32 * *$ & $0.16^{* *}$ & $2.59 * *$ \\
\hline $\begin{array}{l}2 \mathrm{a} . \\
2 \mathrm{~b} .\end{array}$ & $\begin{array}{l}\text { Negative affectivity with the NOSQ } \\
\text { Mood with the NOSQ }\end{array}$ & 392 & $0.22 * *$ & $0.16^{* *}$ & 0.89 \\
\hline $\begin{array}{l}3 \mathrm{a} . \\
3 \mathrm{~b} .\end{array}$ & $\begin{array}{l}\text { Neuroticism with the NOSQ } \\
\text { Mood with the NOSQ }\end{array}$ & 392 & $0.30 * *$ & $0.16^{* *}$ & $2.22 * *$ \\
\hline $\begin{array}{l}4 \mathrm{a} . \\
4 \mathrm{~b} .\end{array}$ & $\begin{array}{l}\text { Extraversion with the NOSQ } \\
\text { Mood with the NOSQ }\end{array}$ & 392 & $0.22 * *$ & $0.16^{* *}$ & 0.89 \\
\hline $\begin{array}{l}5 \mathrm{a} . \\
5 \mathrm{~b} .\end{array}$ & $\begin{array}{l}\text { Trait anxiety with the NOSQ } \\
\text { Mood with the NOSQ }\end{array}$ & 392 & $0.21 * *$ & $0.16^{* *}$ & 0.74 \\
\hline $\begin{array}{l}\text { 6a. } \\
6 \mathrm{~b} .\end{array}$ & $\begin{array}{l}\text { Trait anger with the NOSQ } \\
\text { Mood with the NOSQ }\end{array}$ & 392 & $0.23 * *$ & $0.16^{* *}$ & 1.05 \\
\hline $\begin{array}{l}7 \mathrm{a} . \\
7 \mathrm{~b} .\end{array}$ & $\begin{array}{l}\text { Trait depression with the NOSQ } \\
\text { Mood with the NOSQ }\end{array}$ & 392 & $0.34 * *$ & $0.16^{* *}$ & $2.96^{* *}$ \\
\hline $\begin{array}{l}8 \mathrm{a} . \\
8 \mathrm{~b} .\end{array}$ & $\begin{array}{l}\text { Cheerfulness with the NOSQ } \\
\text { Mood with the NOSQ }\end{array}$ & 392 & $0.29 * *$ & $0.16^{* *}$ & $2.05^{* *}$ \\
\hline
\end{tabular}

Note. ${ }^{*} p<.05 ; * * p<.01$ 
Table 4

Comparison of the Relationship Between the NOSQ and Job Satisfaction with the Relationship Between the NOSQ and Job Cognitions

\begin{tabular}{|c|c|c|c|c|c|}
\hline & Correlations in Comparison & $N$ & First Correlation & Second Correlation & $t$ \\
\hline $\begin{array}{l}\text { 1a. } \\
1 \mathrm{~b} .\end{array}$ & $\begin{array}{l}\text { Job satisfaction with the NOSQ } \\
\text { Job cognitions with the NOSQ }\end{array}$ & 317 & $0.19 * *$ & $0.22 * *$ & -0.39 \\
\hline
\end{tabular}

Note. ${ }^{*} p<.05 ; * *<<.01$ 
Table 5

Regression Analyses of the Unique Variance Explained in the NOSQ by Affective- and Cognitive-Oriented Dispositions

\begin{tabular}{|c|c|c|c|c|}
\hline Dependent Variable & Ordered Predictors & $B$ & $R^{2}$ & $R^{2}$ Change \\
\hline NOSQ & $\begin{array}{l}\text { 1. Affective-oriented dispositions: } \\
\text { Positive affectivity } \\
\text { Negative affectivity } \\
\text { Neuroticism } \\
\text { Extraversion } \\
\text { Trait anxiety } \\
\text { Trait depression } \\
\text { Trait anger } \\
\text { Cheerfulness } \\
\text { 2. Cognitive-oriented dispositions: } \\
\text { Need for cognition } \\
\text { General Self-efficacy } \\
\text { Locus of control }\end{array}$ & $\begin{array}{l}.217^{* *} \\
-.005 \\
.085 \\
.019 \\
.008 \\
-.294^{*} \\
-.089 \\
.127^{*} \\
\\
-.161^{* *} \\
.015 \\
-.091\end{array}$ & . & $.026 * *$ \\
\hline NOSQ & $\begin{array}{l}\text { 1. Cognitive-oriented dispositions: } \\
\text { Need for cognition } \\
\text { General Self-efficacy } \\
\text { Locus of control } \\
\text { 2. Affective-oriented dispositions: } \\
\text { Positive affectivity } \\
\text { Negative affectivity } \\
\text { Neuroticism } \\
\text { Extraversion } \\
\text { Trait anxiety } \\
\text { Trait depression } \\
\text { Trait anger } \\
\text { Cheerfulness }\end{array}$ & $\begin{array}{l}-.161^{* *} \\
.015 \\
-.091 \\
.217^{* *} \\
-.005 \\
.085 \\
.019 \\
.008 \\
-.294^{*} \\
-.089 \\
.127^{*}\end{array}$ & 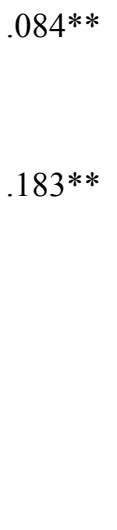 & $.099 * *$ \\
\hline
\end{tabular}

Note. All betas are from the final regression model after the final predictors were added. ${ }^{*} p<.05 ;{ }^{* *} p<.01$. 
Table 6

Regression Analyses of the Unique Variance Explained in the NOSQ by Affective-Oriented Dispositions and Mood

\begin{tabular}{|c|c|c|c|c|}
\hline Dependent Variable & Ordered Predictors & $\beta$ & $R^{2}$ & $R^{2}$ Change \\
\hline NOSQ & $\begin{array}{l}\text { 1. Affective-oriented dispositions: } \\
\text { Positive affectivity } \\
\text { Negative affectivity } \\
\text { Neuroticism } \\
\text { Extraversion } \\
\text { Trait anxiety } \\
\text { Trait depression } \\
\text { Trait anger } \\
\text { Cheerfulness } \\
\text { 2. Mood }\end{array}$ & $\begin{array}{l}.155^{* *} \\
-.003 \\
.049 \\
.012 \\
.053 \\
. .238 \\
-.059 \\
.124^{*} \\
.011\end{array}$ & . & .001 \\
\hline NOSQ & $\begin{array}{l}\text { 1. Mood } \\
\text { 2. Affective-oriented dispositions: } \\
\text { Positive affectivity } \\
\text { Negative affectivity } \\
\text { Neuroticism } \\
\text { Extraversion } \\
\text { Trait anxiety } \\
\text { Trait depression } \\
\text { Trait anger } \\
\text { Cheerfulness }\end{array}$ & $\begin{array}{l}.011 \\
.155^{* *} \\
-.003 \\
.049 \\
.012 \\
.053 \\
-.238 \\
-.059 \\
.124 *\end{array}$ & $\begin{array}{l}.025^{* *} \\
.159^{* *}\end{array}$ & $.134 * *$ \\
\hline
\end{tabular}

Note. All betas are from the final regression model after the final predictors were added. ${ }^{*} p<.05 ;{ }^{* *} p<.01$. 
Neutral Objects Satisfaction Questionnaire 70

\section{Appendix A}

Table 7

Exploratory Regression Analyses of the Unique Variation Explained in Job Satisfaction and Job Cognitions

\begin{tabular}{|c|c|c|c|c|}
\hline Dependent Variable & Ordered Predictors & $\beta$ & $R^{2}$ & $R^{2}$ Change \\
\hline Job Satisfaction & $\begin{array}{l}\text { 1. Affective-oriented dispositions: } \\
\text { Positive affectivity } \\
\text { Negative affectivity } \\
\text { 2. NOSQ }\end{array}$ & $\begin{array}{l}.234^{* *} \\
.002 \\
.116^{*}\end{array}$ & $.072 * *$ & $.013 *$ \\
\hline Job Satisfaction & $\begin{array}{l}\text { 1. All dispositions: } \\
\text { Positive affectivity } \\
\text { Negative affectivity } \\
\text { Neuroticism } \\
\text { Extraversion } \\
\text { Trait anxiety } \\
\text { Trait depression } \\
\text { Trait anger } \\
\text { Cheerfulness } \\
\text { Need for cognition } \\
\text { General Self-efficacy } \\
\text { Locus of control } \\
\text { 2. NOSQ }\end{array}$ & $\begin{array}{l}.272^{* *} \\
-.083 \\
.097 \\
.025 \\
-.009 \\
-.155 \\
.068 \\
-.056 \\
-.186^{* *} \\
.182^{*} \\
-.176 \\
.100\end{array}$ & $.116^{* *}$ & .009 \\
\hline Job Cognitions & $\begin{array}{l}\text { 1. Affective-oriented dispositions: } \\
\text { Positive affectivity } \\
\text { Negative affectivity } \\
\text { 2. NOSQ }\end{array}$ & $\begin{array}{l}.309^{* *} \\
.111 \\
.152^{* *}\end{array}$ & $\begin{array}{l}.107^{* *} \\
.127^{* *}\end{array}$ & $.021^{* *}$ \\
\hline Job Cognitions & $\begin{array}{l}\text { 1. All dispositions: } \\
\text { Positive affectivity } \\
\text { Negative affectivity } \\
\text { Neuroticism } \\
\text { Extraversion } \\
\text { Trait anxiety } \\
\text { Trait depression } \\
\text { Trait anger } \\
\text { Cheerfulness } \\
\text { Need for cognition } \\
\text { General Self-efficacy } \\
\text { Locus of control } \\
\text { 2. NOSQ }\end{array}$ & $\begin{array}{l}.269^{* *} \\
.033 \\
.207 \\
.037 \\
-.005 \\
-.189 \\
.096 \\
-.021 \\
-.099 \\
.155 \\
-.029 \\
.145^{*}\end{array}$ & $.143^{* *}$ & $.018^{*}$ \\
\hline
\end{tabular}

Note. All betas are from the final regression model after the final predictors were added. $*^{*} p .05 ; * * p<.01$. 
Neutral Objects Satisfaction Questionnaire 71

Table 8

Regression Analyses of the Unique Variance Explained in the NOSQ by PA/NA and Cognitive-Oriented Dispositions

\begin{tabular}{|c|c|c|c|c|}
\hline Dependent Variable & Ordered Predictors & $B$ & $R^{2}$ & $R^{2}$ Change \\
\hline NOSQ & $\begin{array}{l}\text { 1. Affective-oriented dispositions: } \\
\text { Positive affectivity } \\
\text { Negative affectivity } \\
\text { 2. Cognitive-oriented dispositions: } \\
\text { Need for cognition } \\
\text { General Self-efficacy } \\
\text { Locus of control }\end{array}$ & $\begin{array}{l}.162^{* *} \\
-.055 \\
-.088^{* *} \\
.008 \\
.061\end{array}$ & $.113 * *$ & $.024 *$ \\
\hline NOSQ & $\begin{array}{l}\text { 1. Cognitive-oriented dispositions: } \\
\text { Need for cognition } \\
\text { General Self-efficacy } \\
\text { Locus of control } \\
\text { 2. Affective-oriented dispositions: } \\
\text { Positive affectivity } \\
\text { Negative affectivity }\end{array}$ & $\begin{array}{l}.162 * * \\
-.055 \\
-.088 * * \\
.008 \\
.061\end{array}$ & $\begin{array}{l}.077 * * \\
.126 * *\end{array}$ & $.053 * *$ \\
\hline
\end{tabular}

Note. All betas are from the final regression model after the final predictors were added. $* p<.05 ; * * p<.01$. 
Table 9

Comparison of the Corrected Correlations Between the NOSQ and Affective-Oriented Dispositions with the Relationships Between the NOSQ and Cognitive-Oriented Dispositions

\begin{tabular}{|c|c|c|c|c|}
\hline & Correlations in Comparison & $N$ & Corrected Correlations & 95\% Confidence Intervals \\
\hline $\begin{array}{l}1 \mathrm{a} . \\
1 \mathrm{~b} .\end{array}$ & $\begin{array}{l}\text { Positive affectivity with the NOSQ } \\
\text { Locus of control with the NOSQ }\end{array}$ & 395 & $\begin{array}{l}.39 * * \\
.27 * *\end{array}$ & $\begin{array}{l}(.30, .47)^{++} \\
(.18, .36)^{++}\end{array}$ \\
\hline $\begin{array}{l}2 \mathrm{a} . \\
2 \mathrm{~b} .\end{array}$ & $\begin{array}{l}\text { Positive affectivity with the NOSQ } \\
\text { Need for cognition with the NOSQ }\end{array}$ & 395 & $\begin{array}{l}.39^{* *} \\
.00\end{array}$ & $\begin{array}{l}(.30, .47)^{++} \\
(-.01, .01)^{++}\end{array}$ \\
\hline $\begin{array}{l}3 \mathrm{a} . \\
3 \mathrm{~b} .\end{array}$ & $\begin{array}{l}\text { Positive affectivity with the NOSQ } \\
\text { General self-efficacy with the NOSQ }\end{array}$ & 395 & $\begin{array}{l}.39 * * \\
.24 * *\end{array}$ & $\begin{array}{l}(.30, .47)^{++} \\
(.15, .33)^{++}\end{array}$ \\
\hline $\begin{array}{l}4 \mathrm{a} . \\
4 \mathrm{~b} .\end{array}$ & $\begin{array}{l}\text { Negative affectivity with the NOSQ } \\
\text { Locus of control with the NOSQ }\end{array}$ & 396 & $\begin{array}{l}.27 * * \\
.27 * *\end{array}$ & $\begin{array}{l}(.18, .36) \\
(.18, .36)\end{array}$ \\
\hline $\begin{array}{l}5 \mathrm{a} . \\
5 \mathrm{~b} .\end{array}$ & $\begin{array}{l}\text { Negative affectivity with the NOSQ } \\
\text { Need for cognition with the NOSQ }\end{array}$ & 395 & $\begin{array}{l}.27^{* *} \\
.00\end{array}$ & $\begin{array}{l}(.18, .36)^{++} \\
(-.01, .01)^{++}\end{array}$ \\
\hline $\begin{array}{l}6 \mathrm{a} . \\
6 \mathrm{~b} .\end{array}$ & $\begin{array}{l}\text { Negative affectivity with the NOSQ } \\
\text { General self-efficacy with the NOSQ }\end{array}$ & 395 & $\begin{array}{l}.27^{* *} \\
.24 * *\end{array}$ & $\begin{array}{l}(.18, .36) \\
(.15, .33)\end{array}$ \\
\hline $\begin{array}{l}7 \mathrm{a} . \\
7 \mathrm{~b} .\end{array}$ & $\begin{array}{l}\text { Neuroticism with the NOSQ } \\
\text { Locus of control with the NOSQ }\end{array}$ & 396 & $\begin{array}{l}.37 * * \\
.27^{* *}\end{array}$ & $\begin{array}{l}(.28, .45)^{++} \\
(.18, .36)^{++}\end{array}$ \\
\hline $\begin{array}{l}8 \mathrm{a} . \\
8 \mathrm{~b} .\end{array}$ & $\begin{array}{l}\text { Neuroticism with the NOSQ } \\
\text { Need for cognition with the NOSQ }\end{array}$ & 395 & $\begin{array}{l}.37^{* *} \\
.00\end{array}$ & $\begin{array}{l}(.28, .45)^{++} \\
(-.01, .01)^{++}\end{array}$ \\
\hline $\begin{array}{l}9 \mathrm{a} . \\
9 \mathrm{~b} .\end{array}$ & $\begin{array}{l}\text { Neuroticism with the NOSQ } \\
\text { General self-efficacy with the NOSQ }\end{array}$ & 395 & $\begin{array}{l}.37^{* *} \\
.24^{* *}\end{array}$ & $\begin{array}{l}(.28, .45)^{++} \\
(.15, .33)^{++}\end{array}$ \\
\hline $\begin{array}{l}10 \mathrm{a} . \\
10 \mathrm{~b} .\end{array}$ & $\begin{array}{l}\text { Extraversion with the NOSQ } \\
\text { Locus of control with the NOSQ }\end{array}$ & 395 & $\begin{array}{l}.27 * * \\
.27 * *\end{array}$ & $\begin{array}{l}(.18, .36) \\
(.18, .36)\end{array}$ \\
\hline
\end{tabular}

Note. Corrected Correlations represent the absolute value of the respected relationship. ${ }^{++}$Confidence Interval does not contain the respective correlation in the comparison. ${ }^{*} p<.05 ; * * p<.01$ 


\section{Neutral Objects Satisfaction Questionnaire 73}

Table 9 continued

Comparison of the Corrected Correlations Between the NOSQ and Affective-Oriented Dispositions with the Relationships Between the NOSQ and Cognitive-Oriented Dispositions

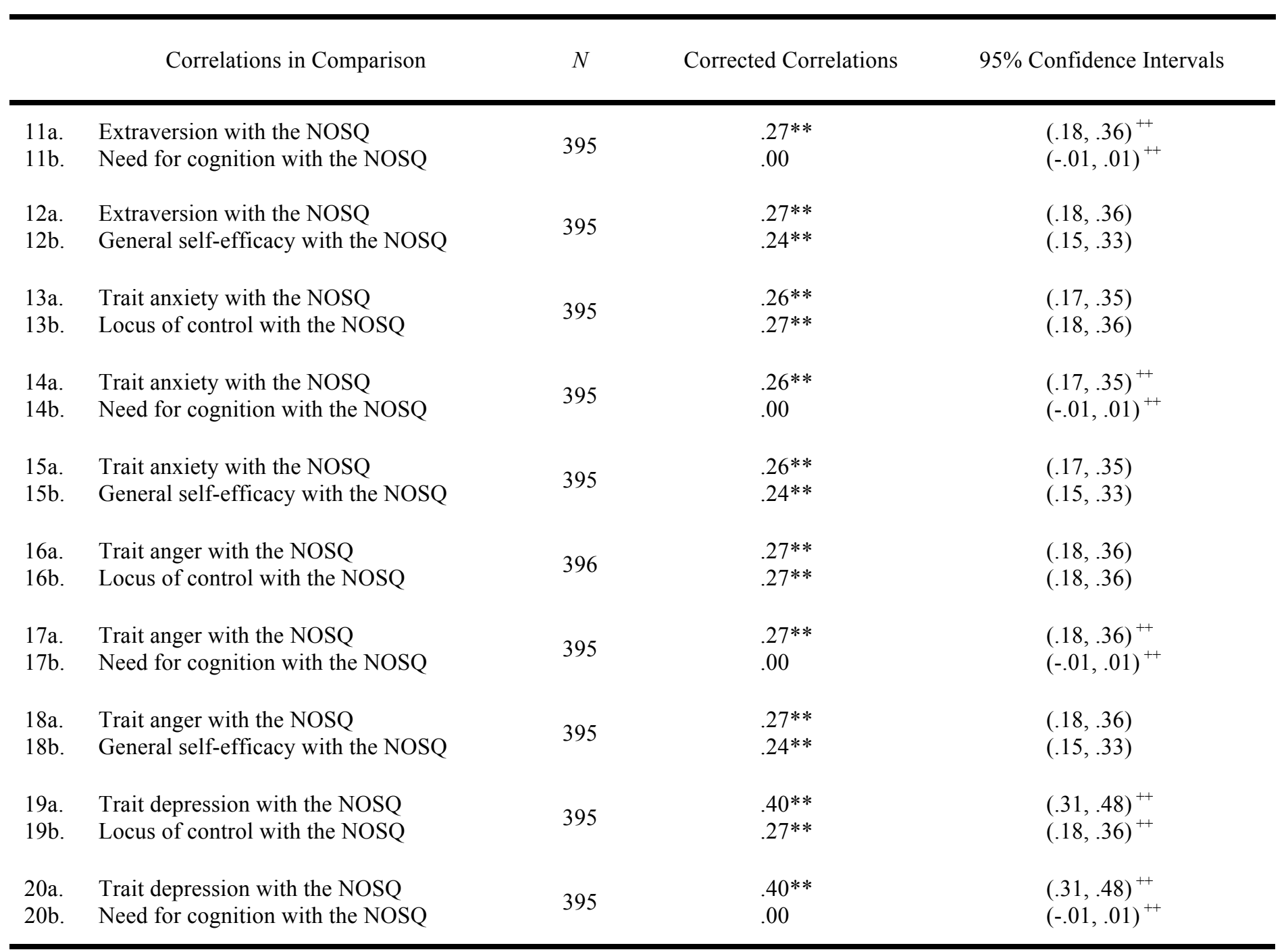

Note. Corrected Correlations represent the absolute value of the respected relationship. ${ }^{++}$Confidence Interval does not contain the respective correlation in the comparison. $* p<.05 ; * * p<.01$ 
Table 9 continued

Comparison of the Corrected Correlations Between the NOSQ and Affective-Oriented Dispositions with the Relationships Between the NOSQ and Cognitive-Oriented Dispositions

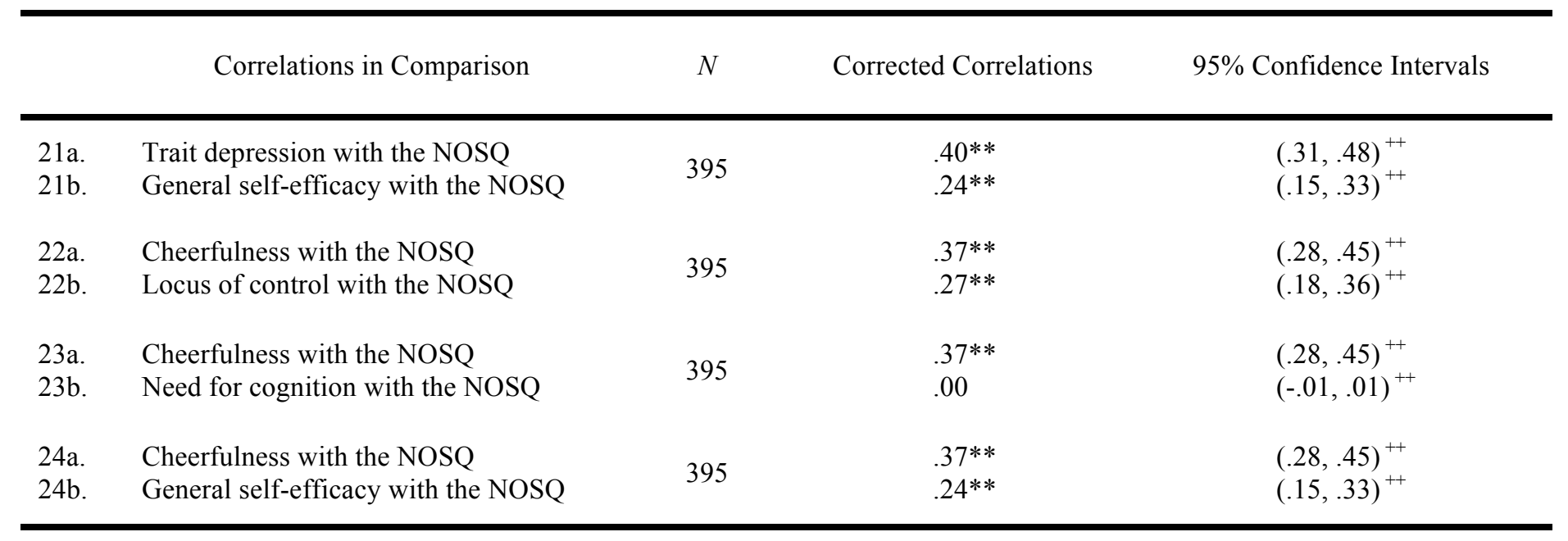

Note. Corrected Correlations represent the absolute value of the respected relationship. ${ }^{++}$Confidence Interval does not contain the respective correlation in the comparison. $* p<.05 ; * * p<.01$. 


\section{Appendix B (Survey)}

\section{Section A}

Please circle the appropriate number on each of the following scales that best describes how you feel right now, todav.

\begin{tabular}{|c|c|c|c|c|c|c|}
\hline $\begin{array}{c}\text { Very passive } \\
1\end{array}$ & 2 & 3 & 4 & 5 & 6 & $\begin{array}{c}\text { Very active } \\
7\end{array}$ \\
\hline $\begin{array}{c}\text { Very happy } \\
1\end{array}$ & 2 & 3 & 4 & 5 & 6 & $\begin{array}{c}\text { Very sad } \\
7\end{array}$ \\
\hline $\begin{array}{c}\text { Very depressed } \\
1\end{array}$ & 2 & 3 & 4 & 5 & 6 & $\begin{array}{c}\text { Very elated } \\
7\end{array}$ \\
\hline $\begin{array}{c}\text { Very excited } \\
1\end{array}$ & 2 & 3 & 4 & 5 & 6 & $\begin{array}{c}\text { Very tranquil } \\
7\end{array}$ \\
\hline
\end{tabular}

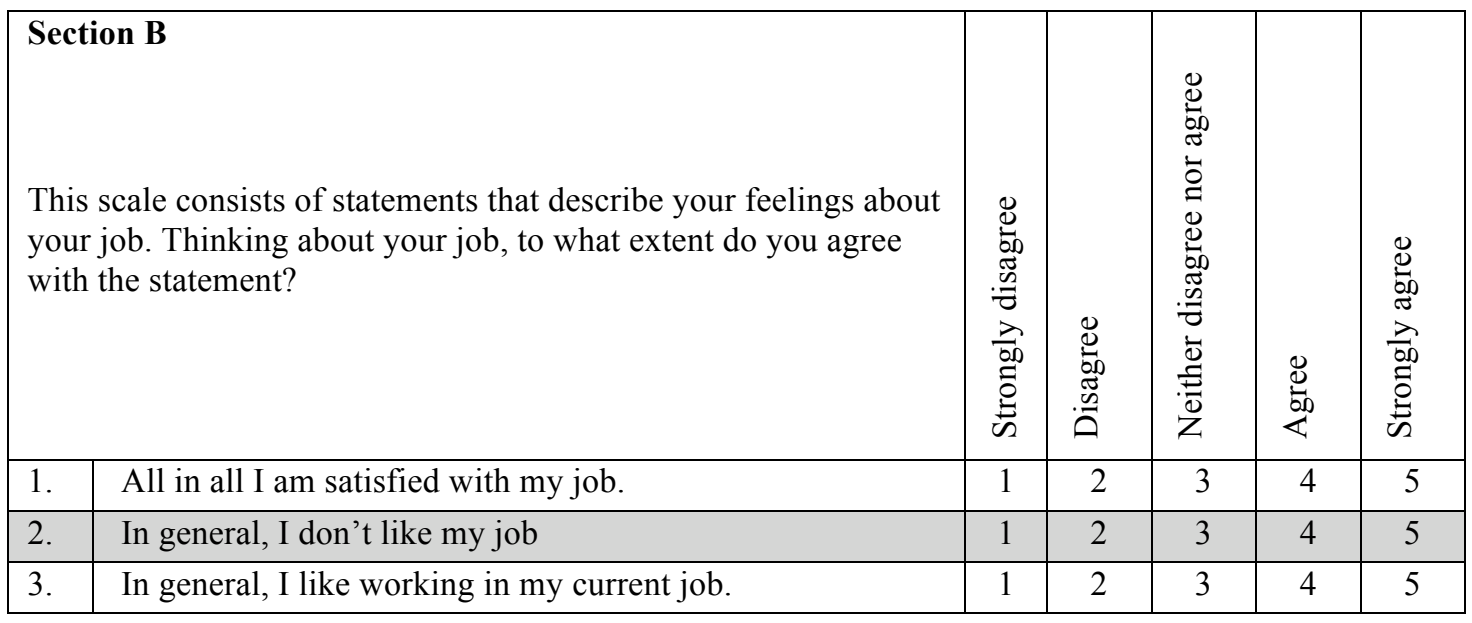




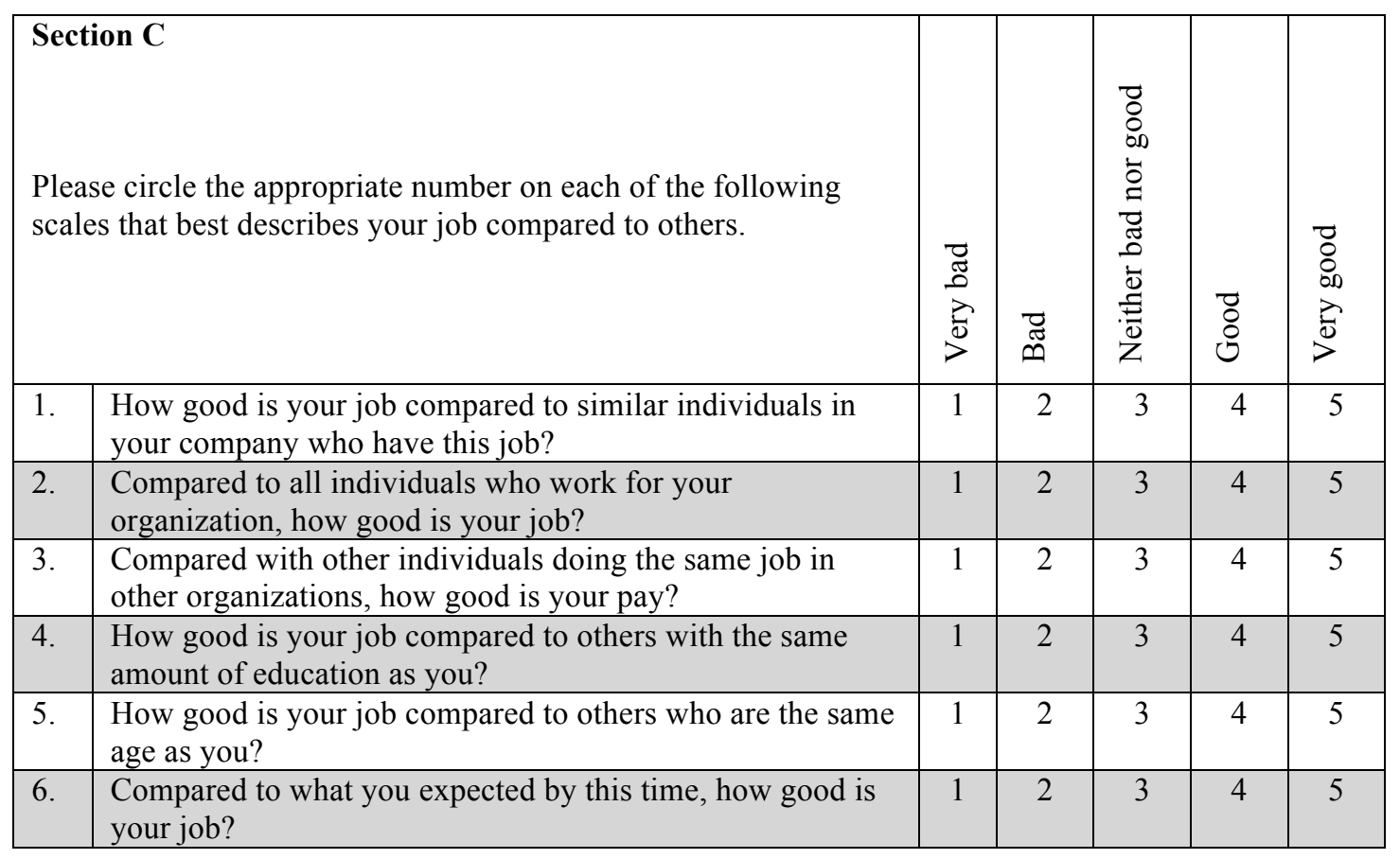

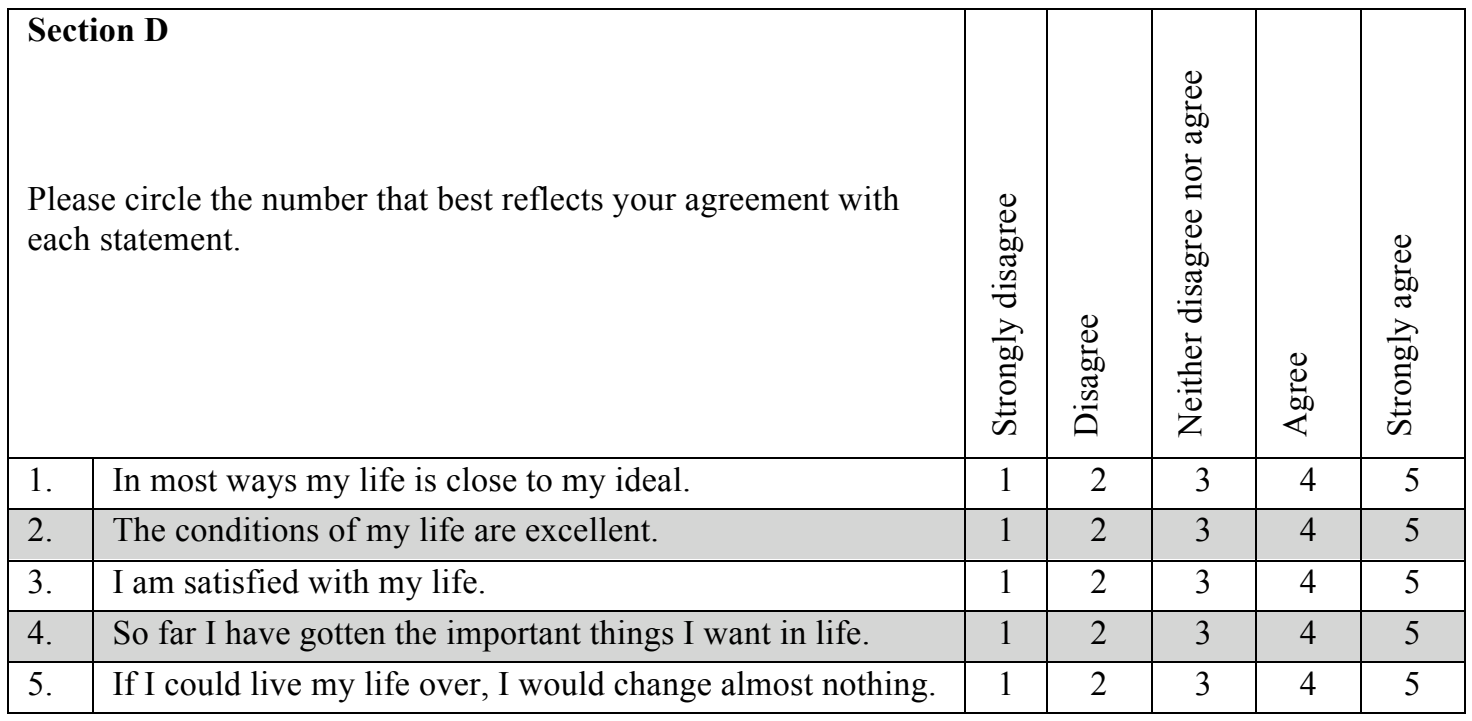




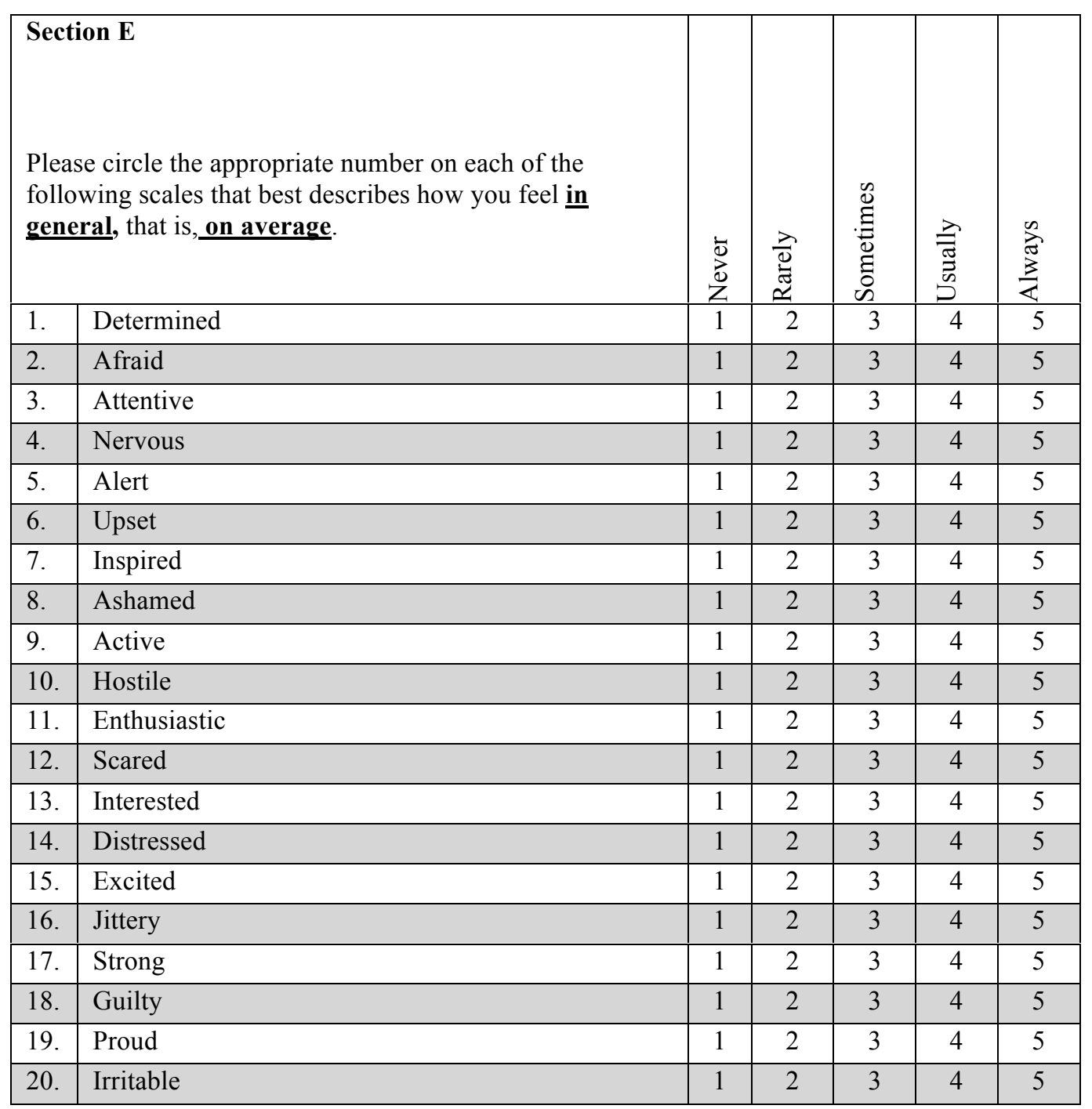




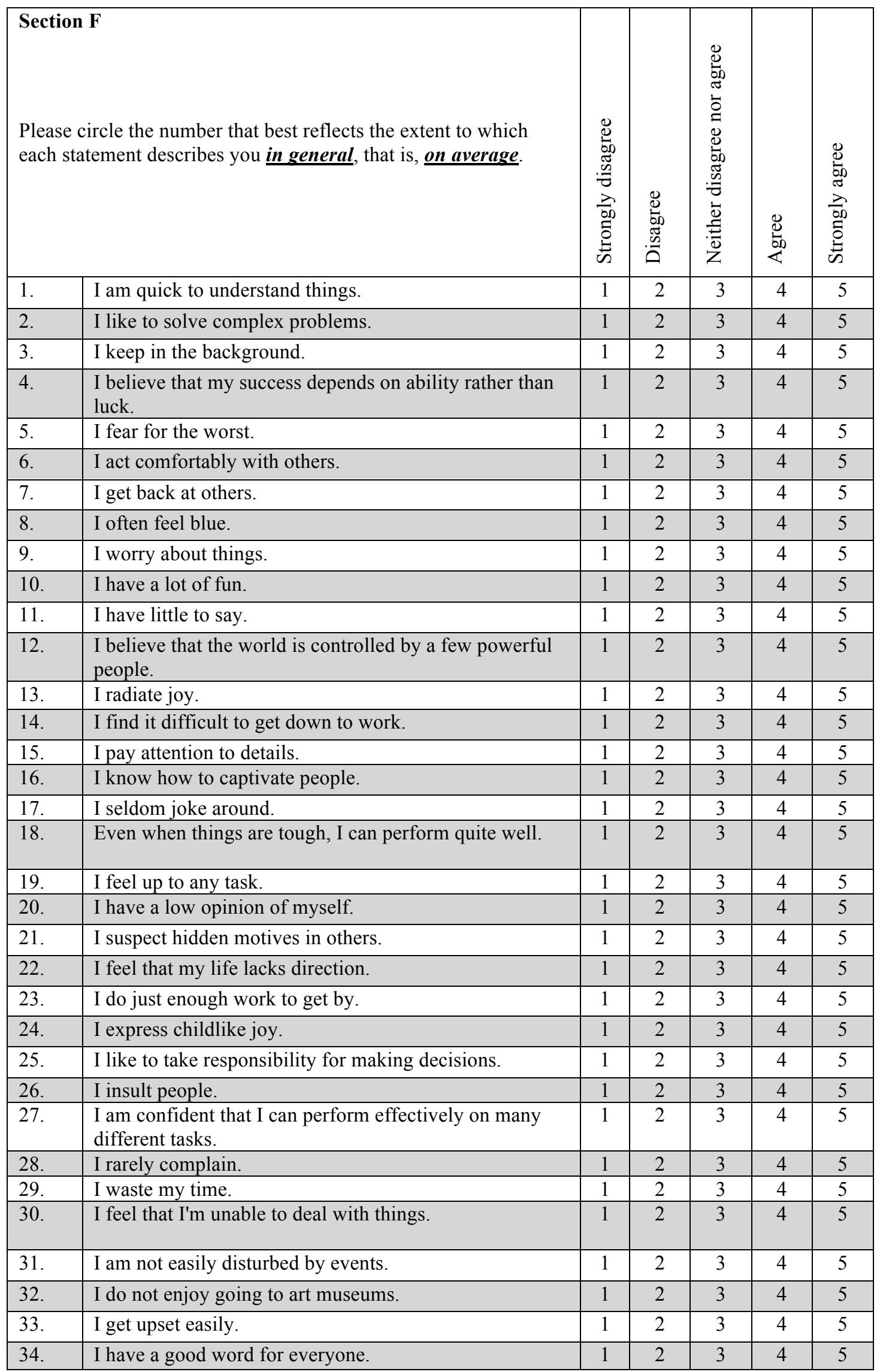




\begin{tabular}{|c|c|c|c|c|c|c|}
\hline \multicolumn{2}{|c|}{$\begin{array}{l}\text { Please circle the number that best reflects the extent to which } \\
\text { each statement describes you in general, that is, on average. }\end{array}$} & 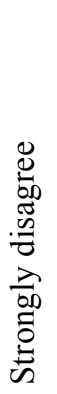 & 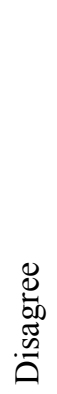 & 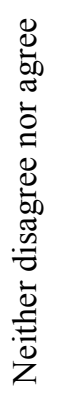 & $\begin{array}{l}\stackrel{8}{ \pm} \\
\stackrel{5}{4}\end{array}$ & 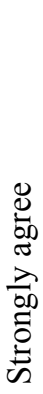 \\
\hline 35. & $\begin{array}{l}\text { In general, I think that I can obtain outcomes that are } \\
\text { important to me. }\end{array}$ & 1 & 2 & 3 & 4 & 5 \\
\hline 36. & I take the initiative. & 1 & 2 & 3 & 4 & 5 \\
\hline 37. & I see difficulties everywhere. & 1 & 2 & 3 & 4 & 5 \\
\hline 38. & I shirk my duties. & 1 & 2 & 3 & 4 & 5 \\
\hline 39. & I believe in the importance of art. & 1 & 2 & 3 & 4 & 5 \\
\hline 40. & I am often in a bad mood. & 1 & 2 & 3 & 4 & 5 \\
\hline 41. & I laugh aloud. & 1 & 2 & 3 & 4 & 5 \\
\hline 42. & I am not interested in abstract ideas. & 1 & 2 & 3 & 4 & 5 \\
\hline 43. & I love to think up new ways of doing things. & 1 & 2 & 3 & 4 & 5 \\
\hline 44. & I need things explained only once. & 1 & 2 & 3 & 4 & 5 \\
\hline 45. & I am less capable than most people. & 1 & 2 & 3 & 4 & 5 \\
\hline 46. & I am the life of the party. & 1 & 2 & 3 & 4 & 5 \\
\hline 47. & Compared to other people, I can do most tasks very well. & 1 & 2 & 3 & 4 & 5 \\
\hline 48. & I dislike myself. & 1 & 2 & 3 & 4 & 5 \\
\hline 49. & I accept people as they are. & 1 & 2 & 3 & 4 & 5 \\
\hline 50. & $\begin{array}{l}\text { When facing difficult tasks, I am certain that I will } \\
\text { accomplish them. }\end{array}$ & 1 & 2 & 3 & 4 & 5 \\
\hline 51. & I just know that I will be a success. & 1 & 2 & 3 & 4 & 5 \\
\hline 52. & I tend to vote for conservative political candidates. & 1 & 2 & 3 & 4 & 5 \\
\hline 53. & I have a vivid imagination. & 1 & 2 & 3 & 4 & 5 \\
\hline 54. & I don't worry about things that have already happened. & 1 & 2 & 3 & 4 & 5 \\
\hline 55. & I get irritated easily. & 1 & 2 & 3 & 4 & 5 \\
\hline 56. & I habitually blow my chances. & 1 & 2 & 3 & 4 & 5 \\
\hline 57. & I rarely get irritated. & 1 & 2 & 3 & 4 & 5 \\
\hline 58. & I am often down in the dumps. & 1 & 2 & 3 & 4 & 5 \\
\hline 59. & I make plans and stick to them. & 1 & 2 & 3 & 4 & 5 \\
\hline 60. & I am relaxed most of the time. & 1 & 2 & 3 & 4 & 5 \\
\hline 61. & I have a sharp tongue. & 1 & 2 & 3 & 4 & 5 \\
\hline 62. & I make a decision and move on. & 1 & 2 & 3 & 4 & 5 \\
\hline 63. & I keep my cool. & 1 & 2 & 3 & 4 & 5 \\
\hline 64. & I would describe my experiences as somewhat dull. & 1 & 2 & 3 & 4 & 5 \\
\hline 65. & I seldom feel blue. & 1 & 2 & 3 & 4 & 5 \\
\hline 66. & I feel comfortable around people. & 1 & 2 & 3 & 4 & 5 \\
\hline 67. & I try to avoid complex people. & 1 & 2 & 3 & 4 & 5 \\
\hline 68. & I make friends easily. & 1 & 2 & 3 & 4 & 5 \\
\hline 69. & I am not easily annoyed. & 1 & 2 & 3 & 4 & 5 \\
\hline
\end{tabular}




\begin{tabular}{|c|c|c|c|c|c|c|}
\hline \multicolumn{2}{|c|}{$\begin{array}{l}\text { Please circle the number that best reflects the extent to which } \\
\text { each statement describes you in general, that is, on average. }\end{array}$} & 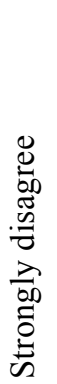 & 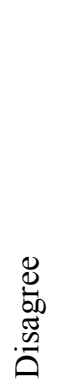 & 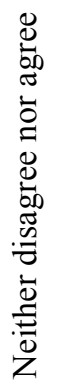 & $\underset{\mathscr{E}}{\stackrel{8}{5}}$ & 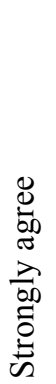 \\
\hline 70. & I avoid difficult reading material. & 1 & 2 & 3 & 4 & 5 \\
\hline 71. & I believe that others have good intentions. & 1 & 2 & 3 & 4 & 5 \\
\hline 72. & I get chores done right away. & 1 & 2 & 3 & 4 & 5 \\
\hline 73. & I believe some people are born lucky. & 1 & 2 & 3 & 4 & 5 \\
\hline 74. & I love life. & 1 & 2 & 3 & 4 & 5 \\
\hline 75. & I panic easily. & 1 & 2 & 3 & 4 & 5 \\
\hline 76. & I have frequent mood swings. & 1 & 2 & 3 & 4 & 5 \\
\hline 77. & I seldom get mad. & 1 & 2 & 3 & 4 & 5 \\
\hline 78. & I am not easily bothered by things. & 1 & 2 & 3 & 4 & 5 \\
\hline 79. & I cut others to pieces. & 1 & 2 & 3 & 4 & 5 \\
\hline 80. & I enjoy hearing new ideas. & 1 & 2 & 3 & 4 & 5 \\
\hline 81. & I am very pleased with myself. & 1 & 2 & 3 & 4 & 5 \\
\hline 82. & I get stressed out easily. & 1 & 2 & 3 & 4 & 5 \\
\hline 83. & I get caught up in my problems. & 1 & 2 & 3 & 4 & 5 \\
\hline 84. & I am skilled in handling social situations. & 1 & 2 & 3 & 4 & 5 \\
\hline 85. & I tend to vote for liberal political candidates. & 1 & 2 & 3 & 4 & 5 \\
\hline 86. & I love to read challenging material. & 1 & 2 & 3 & 4 & 5 \\
\hline 87. & I feel comfortable with myself. & 1 & 2 & 3 & 4 & 5 \\
\hline 88. & $\begin{array}{l}\text { I believe I can succeed at most any endeavor to which I } \\
\text { set my mind. }\end{array}$ & 1 & 2 & 3 & 4 & 5 \\
\hline 89. & I am afraid of many things. & 1 & 2 & 3 & 4 & 5 \\
\hline 90. & I get angry easily. & 1 & 2 & 3 & 4 & 5 \\
\hline 91. & I laugh my way through life. & 1 & 2 & 3 & 4 & 5 \\
\hline 92. & I carry out my plans. & 1 & 2 & 3 & 4 & 5 \\
\hline 93. & I do not like art. & 1 & 2 & 3 & 4 & 5 \\
\hline 94. & I avoid philosophical discussions. & 1 & 2 & 3 & 4 & 5 \\
\hline 95. & $\begin{array}{l}\text { I will be able to achieve most of the goals that I have set } \\
\text { for myself. }\end{array}$ & 1 & 2 & 3 & 4 & 5 \\
\hline 96. & I amuse my friends. & 1 & 2 & 3 & 4 & 5 \\
\hline 97. & I am always prepared. & 1 & 2 & 3 & 4 & 5 \\
\hline 98. & I feel desperate. & 1 & 2 & 3 & 4 & 5 \\
\hline 99. & I don't like to draw attention to myself. & 1 & 2 & 3 & 4 & 5 \\
\hline 100. & I don't talk a lot. & 1 & 2 & 3 & 4 & 5 \\
\hline 101. & I have difficulty understanding abstract ideas. & 1 & 2 & 3 & 4 & 5 \\
\hline 102. & I lose my temper. & 1 & 2 & 3 & 4 & 5 \\
\hline 103. & I will be able to successfully overcome many challenges & 1 & 2 & 3 & 4 & 5 \\
\hline
\end{tabular}


Neutral Objects Satisfaction Questionnaire 81

\begin{tabular}{|l|l|c|c|c|c|c|}
\hline 104. & I look at the bright side of life. & 1 & 2 & 3 & 4 & 5 \\
\hline 105. & I adapt easily to new situations. & 1 & 2 & 3 & 4 & 5 \\
\hline 106. & I dislike taking responsibility for making decisions. & 1 & 2 & 3 & 4 & 5 \\
\hline 107. & I carry the conversation to a higher level. & 1 & 2 & 3 & 4 & 5 \\
\hline 108. & I don't see things through. & 1 & 2 & 3 & 4 & 5 \\
\hline 109. & I come up with good solutions. & 1 & 2 & 3 & 4 & 5 \\
\hline 110. & I respect others. & 1 & 2 & 3 & 4 & 5 \\
\hline 111. & I can handle a lot of information. & 1 & 2 & 3 & 4 & 5 \\
\hline 112. & I am not easily amused. & 1 & 2 & 3 & 4 & 5 \\
\hline 113. & $\begin{array}{l}\text { I believe that unfortunate events occur because of bad } \\
\text { luck. }\end{array}$ & 1 & 2 & 3 & 4 & 5 \\
\hline 114. & I make people feel at ease. & 1 & 2 & 3 & 4 & 5 \\
\hline
\end{tabular}

\begin{tabular}{|c|c|c|c|c|}
\hline \multicolumn{2}{|r|}{$\begin{array}{l}\text { Section G } \\
\text { The following items ask about how you feel in general, that is, } \underline{\text { on }} \\
\text { average. Using the scale below, circle your degree of satisfaction to each } \\
\text { item. }\end{array}$} & \multirow[t]{2}{*}{ 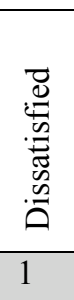 } & \multirow{2}{*}{$\begin{array}{l}\overline{\widetilde{I}} \\
\bar{\Xi} \\
2\end{array}$} & \multirow{2}{*}{ 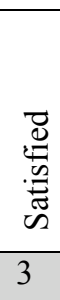 } \\
\hline 1. & The city in which you live. & & & \\
\hline 2. & The residence where you live. & 1 & 2 & 3 \\
\hline 3. & The neighbors you have. & 1 & 2 & 3 \\
\hline 4. & The high school you attended. & 1 & 2 & 3 \\
\hline 5. & The climate where you live. & 1 & 2 & 3 \\
\hline 6. & The movies being produced today. & 1 & 2 & 3 \\
\hline 7. & The quality of food you buy. & 1 & 2 & 3 \\
\hline 8. & Today's cars. & 1 & 2 & 3 \\
\hline 9. & Local newspapers. & 1 & 2 & 3 \\
\hline 10. & Your relaxation time. & 1 & 2 & 3 \\
\hline 11. & Your first name. & 1 & 2 & 3 \\
\hline 12. & The people you know. & 1 & 2 & 3 \\
\hline 13. & Television programs. & 1 & 2 & 3 \\
\hline 14. & Local speed limits. & 1 & 2 & 3 \\
\hline 15. & The way people drive. & 1 & 2 & 3 \\
\hline 16. & Advertising. & 1 & 2 & 3 \\
\hline 17. & The way you were raised. & 1 & 2 & 3 \\
\hline 18. & Telephone services. & 1 & 2 & 3 \\
\hline 19. & Public transportation. & 1 & 2 & 3 \\
\hline 20. & Restaurant food. & 1 & 2 & 3 \\
\hline 21. & Yourself. & 1 & 2 & 3 \\
\hline 22. & Modern art. & 1 & 2 & 3 \\
\hline 23. & Popular music. & 1 & 2 & 3 \\
\hline 24. & $81 / 2 " x 11 "$ piece of paper. & 1 & 2 & 3 \\
\hline 25. & Your telephone number. & 1 & 2 & 3 \\
\hline
\end{tabular}


Neutral Objects Satisfaction Questionnaire 82

\section{Section H: Demographics}

1. What is your age? years

2. How long have you worked in your current job? months

3. How many hours per week do you work in your current job? hours

4. What is your gender (circle one)? Female Male

5. Job title:

6. What is your ethnic identification?
a) Caucasian
b) African-American
c) Asian
d) Native American
e) Hispanic
f) Other: 